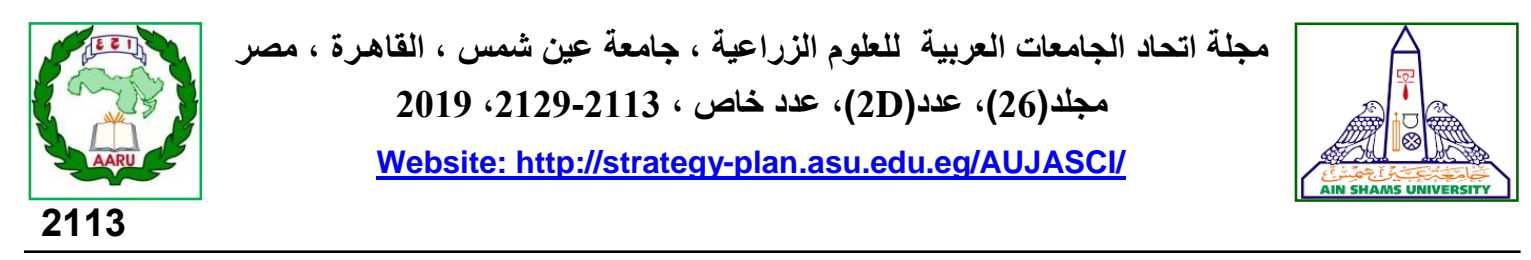

تقييم إقتصادي لمشروع التنمية الريفية المرحلة الثانية كأحد المشروعات المموية اجنبيا

[155]

$$
\text { قسم الاقتصاد الزراعي - كلية الزراعة عبدالصبور أمير أحمد" - وحيد علي مجاهد - عبدالله محمود عبد المقصود } 68 \text { - } 68 \text { - حدائق شبرا } 11241 \text { - القاهرة - مصر }
$$

*Corresponding author: Drahmedamir1982@yahoo.com

Received 12 June, 2018 Accepted 15 July, 2018

دفع المشروع الي ضنخ جزء كبير من تمويل المشروع علي انشطة التدريب.

الكلمات الدالة: التتمية الريفية، التقييم الاقتصادي، التئة

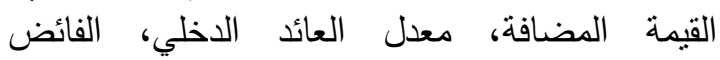
الاجنماعي

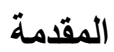

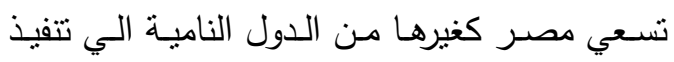

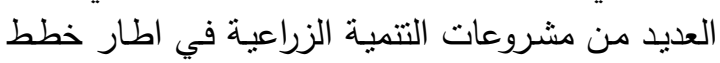

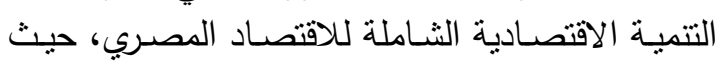

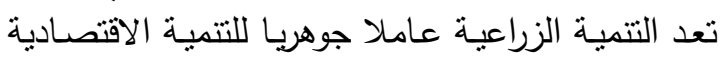

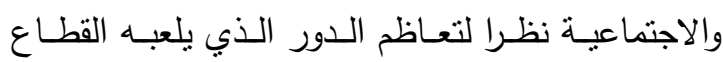

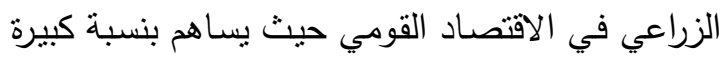

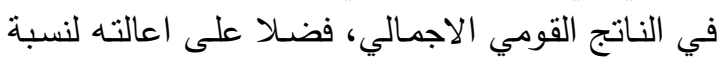

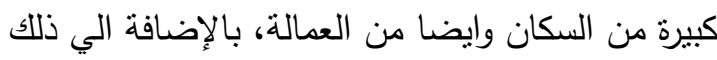

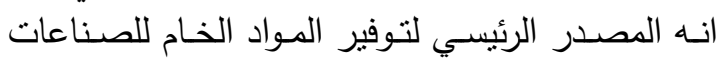

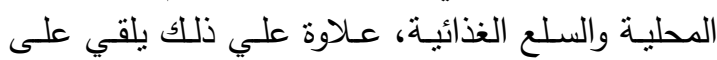

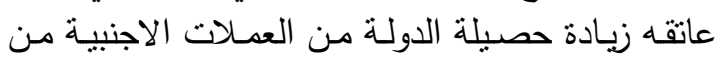

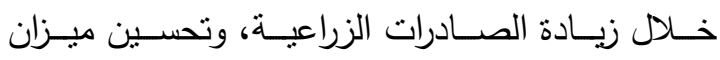
المدفوعات.

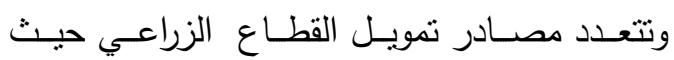

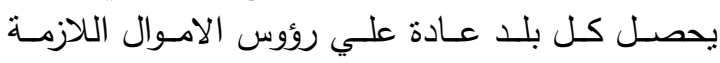

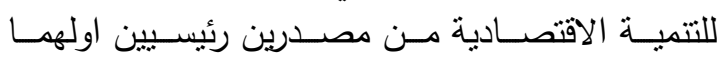

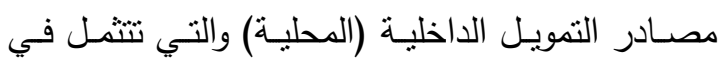

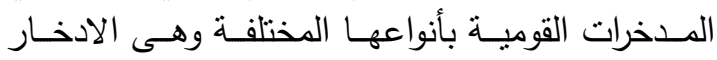

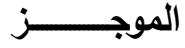

استهدف هذا البحث بشكل عام دراسة اقتصادية لتقييم مشروع التتمية الريفية بالبحيرة المرحلة الثنانية

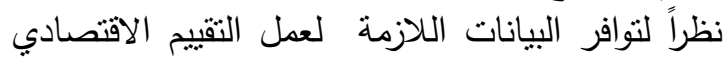

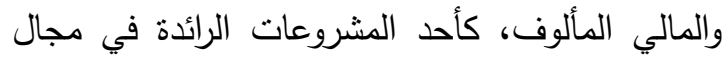

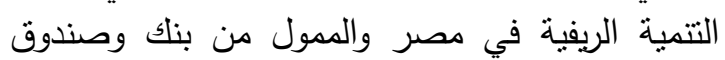
التتمية الافريقي حيث استهدف البحث دراسة مواطن

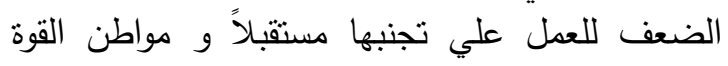

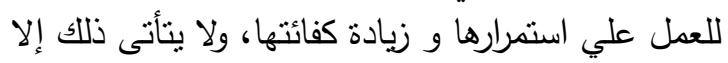

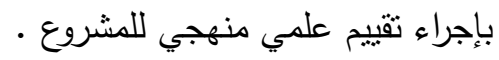

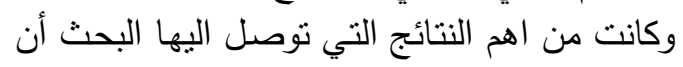

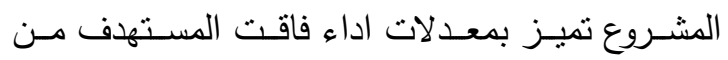

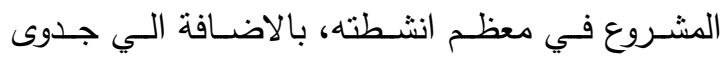

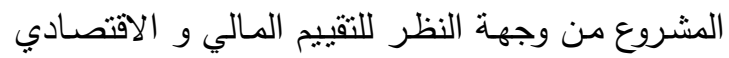

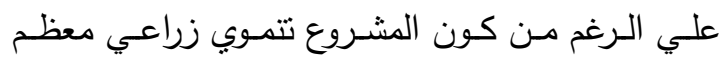

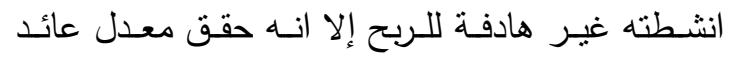

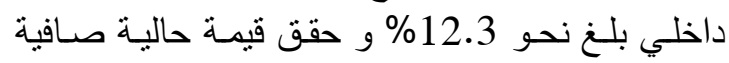

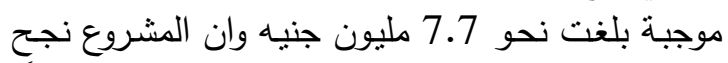

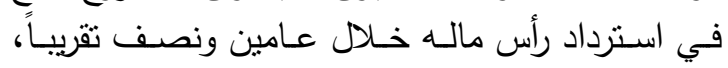

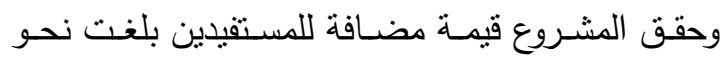
23.6 مليون جنيه في حين حقق قيمة مضافة قلئة قوميـة

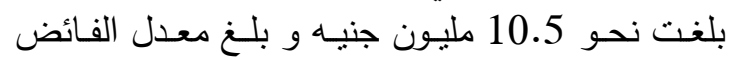

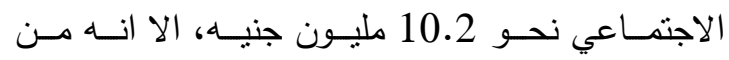

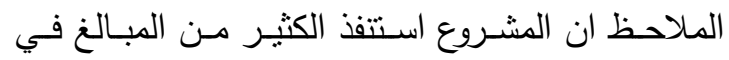

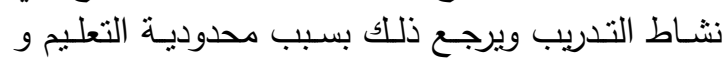

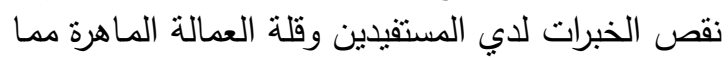


المنهج التحليلي ومصادر الحصول علي البيانات

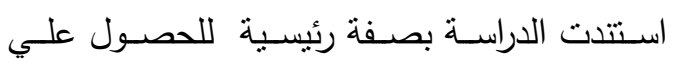

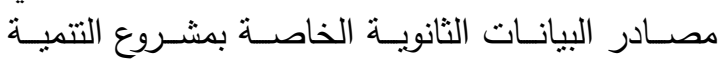

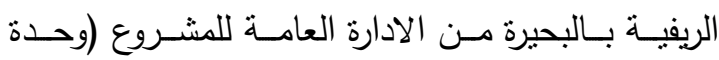

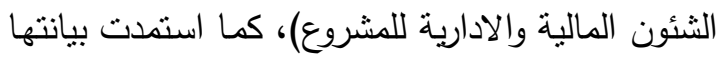

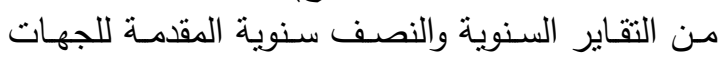

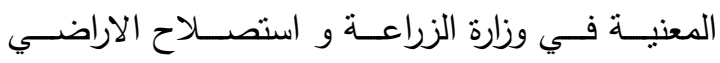

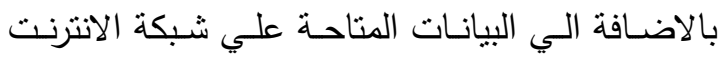

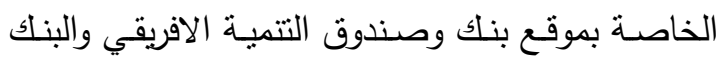

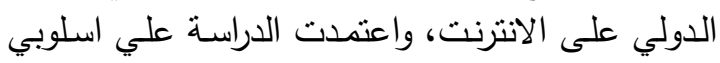

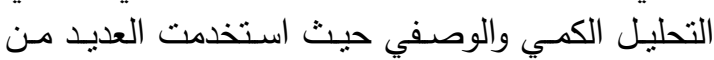

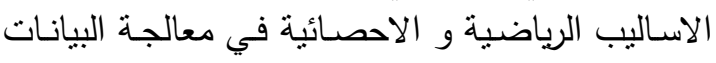

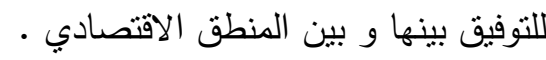

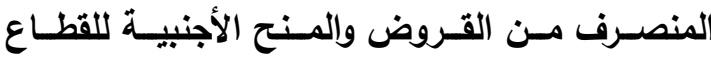 الزراعي وفقا لاهم شركاء التنمية المروفية}

يوضح الجدول (1) جملة المنح والقروض المقدمة

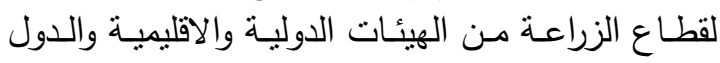

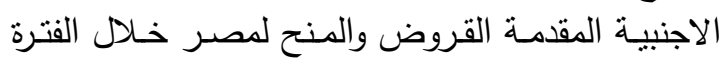

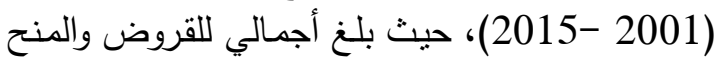
نحو 2628.2 مليون دولار أمريكي.

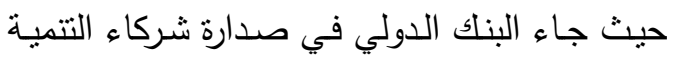

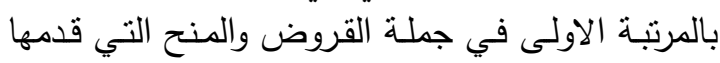

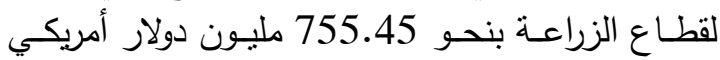

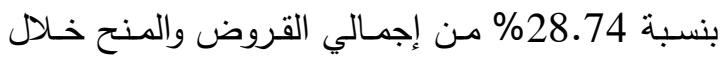

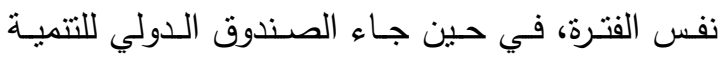

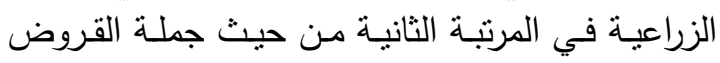

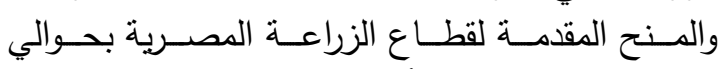
281.99 مليون دولار أمريكي بنسبة بلغت الزراعة 10.73

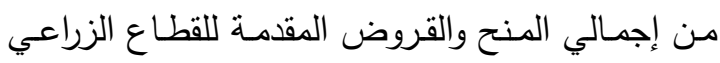

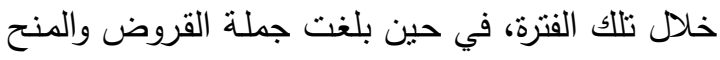
التي قدمها الصندوق السعودي للتنمية 274.46 مليون

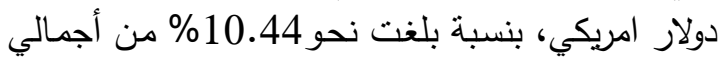

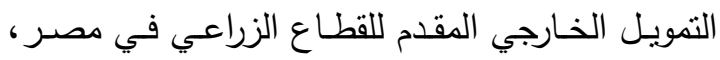

والضرائب والتمويل بالتضخم النقدي، والمصدر الثاني

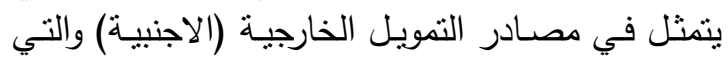

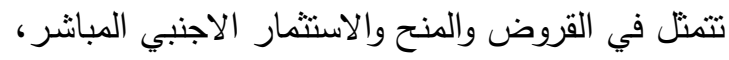

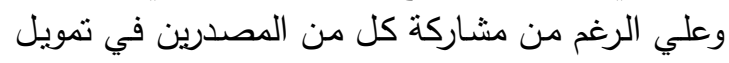

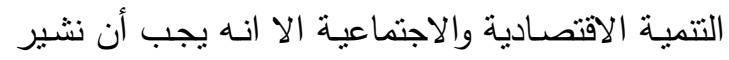

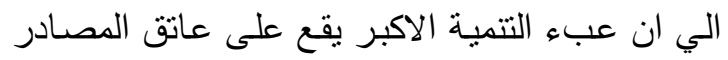

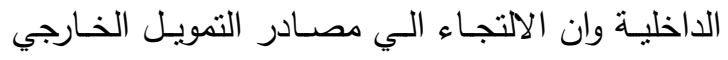

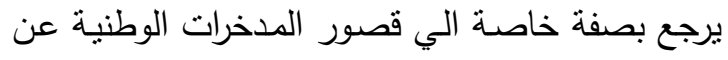

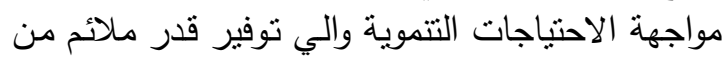

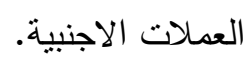

\section{أهمية البحث}

تتشير معظم الدراسـات في مجـال التتميـة الي ان نجاح اي جهود نتموية يعتمد بدرجة كبيرة علي منابعة لتهات

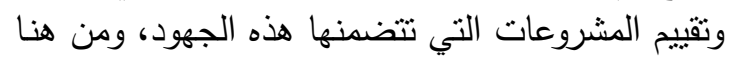

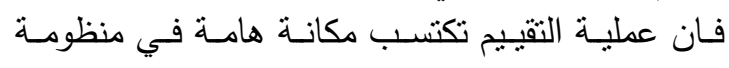

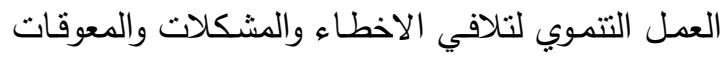

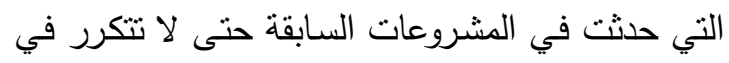

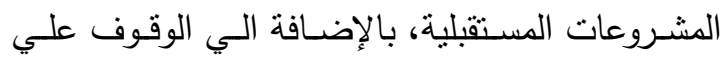

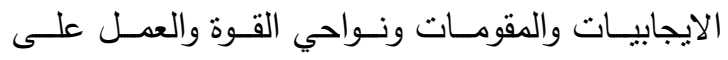

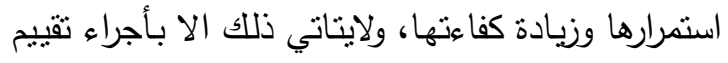
علمي منهجي لمشروعات التتمية الزراعية الريفية.

\section{مشكلة وهدف البحث}

تكمن مشكلة البحث في ان نجاح اي جهود تتموية

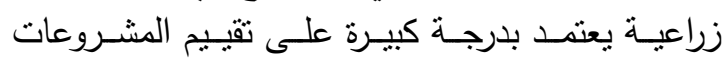

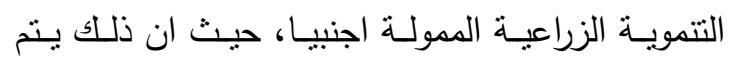

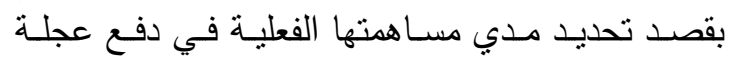

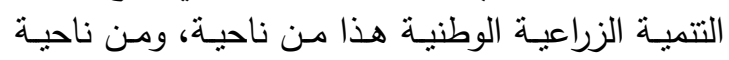

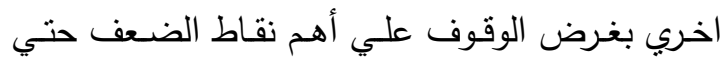

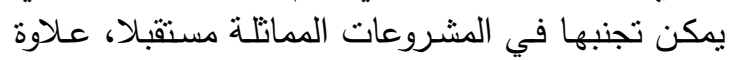

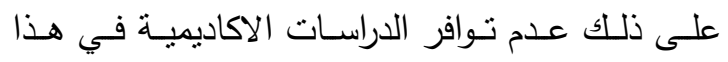

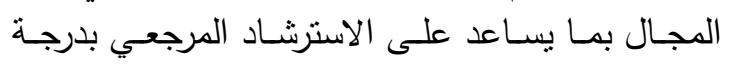
كافية. 


\section{تقييم إقتصادي لمشروع التنمية الريفية المرحلة الثانية كأحد المشروعات الممولة اجنبيا 2115}

حتى المركز الثالث عشر وهي (الصندوق العربي

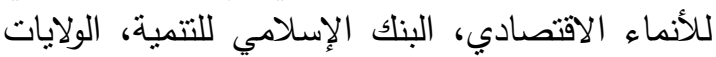

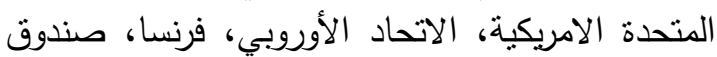

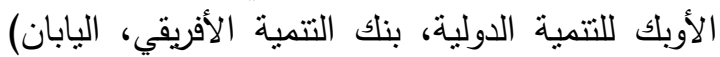

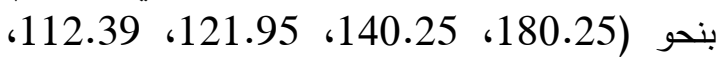

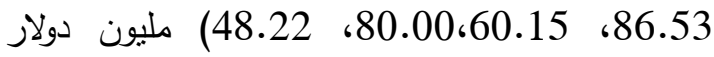

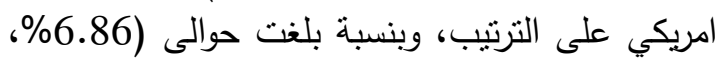

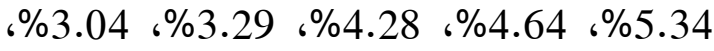

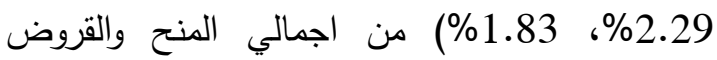
الاجنبية المقدمة لقطاع الزراعة المصرية خلال نفس الفس الفرض
وجاءت المانيا في المركز الرابع بنحو 239.17 مليون

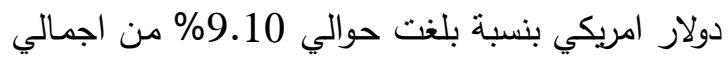

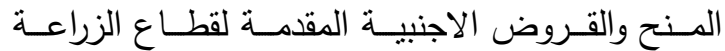

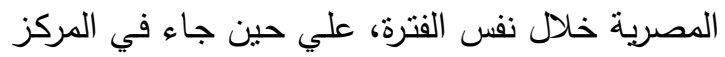

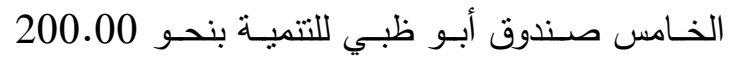

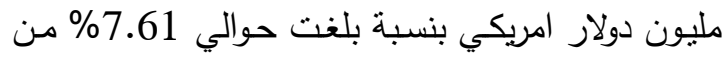

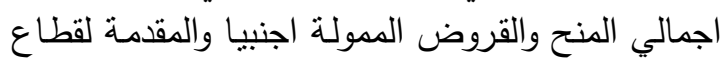
الزراعة المصرية خلال نفس الفترة.

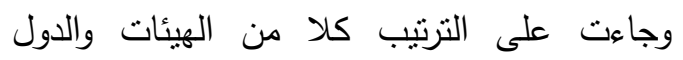

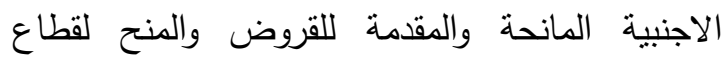
الزراعة المصرية على النحو التالي من المركز السادس المن

جدول 1. توزيع إجمالي المنصرف من القروض والمنح الأجنبية للقطاع الزراعي وفقا لاهم شركاء التتمية خلال الفترة (2001- تُبع الجي

(ب مليون دولار)

\begin{tabular}{|c|c|c|}
\hline الاهمية النسبية \% & المنصرف للقطاع الزراعي & شريك التنمية \\
\hline 28.74 & 755.45 & البنك الدولي \\
\hline 10.73 & 281.99 & الصندوق الدولى للتتمية الزراعية \\
\hline 10.44 & 274.46 & الصندوق السعودي للتتمية \\
\hline 9.10 & 239.17 & المانيا \\
\hline 7.61 & 200.00 & صندوق أبو ظبي للتتمية \\
\hline 6.86 & 180.25 & الصندوق العربي للأنماء الاقتصادي \\
\hline 5.34 & 140.25 & البنك الإسلامي للتتمية \\
\hline 4.64 & 121.95 & الولايات المتحدة الامريكية \\
\hline 4.28 & 112.39 & الاتحاد الأوروبي \\
\hline 3.29 & 86.53 & فرنسا \\
\hline 3.04 & 80.00 & صندوق الأوبك للتتمية الدولية \\
\hline 2.29 & 60.15 & بنأك التتمية الأفريقي \\
\hline 1.83 & 48.22 & 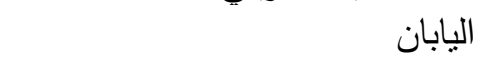 \\
\hline 1.80 & 47.41 & 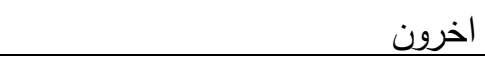 \\
\hline 100 & 2628.2 & الاجمالي \\
\hline
\end{tabular}

المصدر: جمعت وحسبت من موقع بيانات البنك الدولي على شبكةالانترنت .

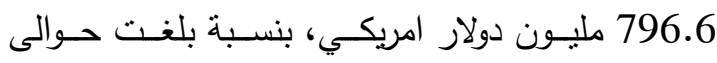

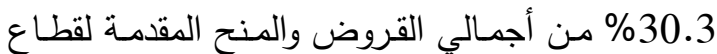
الزراعة، وجدير بالذكر أن مجال الموارد المائية يعتبر

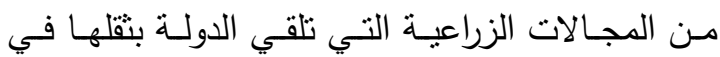

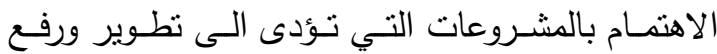

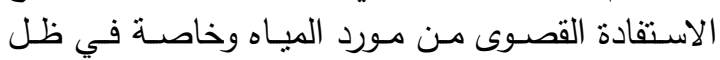
الازمات والمشاكل الحالية والمتوقعة.
التوزيع القطاعي لقيم القروض و المنح الموزعة علي الانشطة الزراعية

يوضـــح الجـدول رقـم (2) بـأن التوزيــع النسبـي

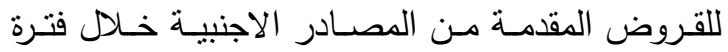

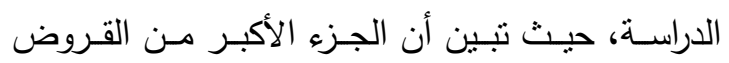

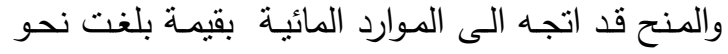




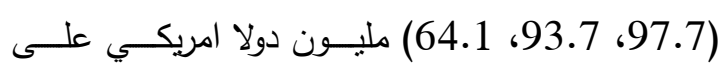

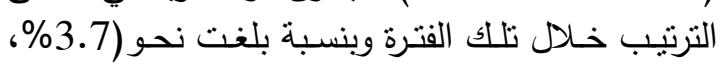

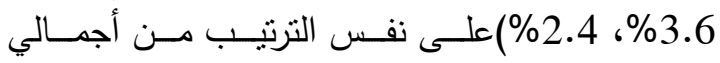
القروض والمنح المقدمة لقطاع الزراعة في مصر . فئل اما بالنسبة للانشطة الزراعية التالية وهي (الامتداد

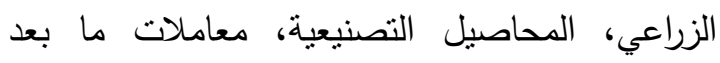

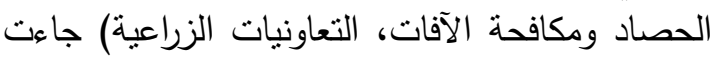

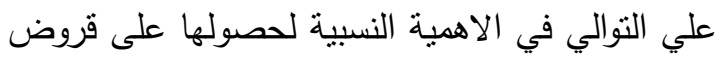

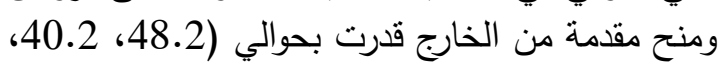

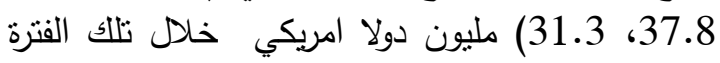

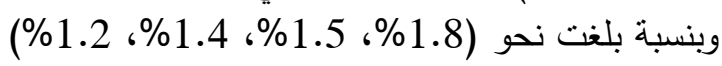
على نفس الترتيب من إجمالي القروض والمن

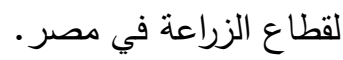

يلي ذلـك في الاهيـة النسـبية نشـاط السياسـية

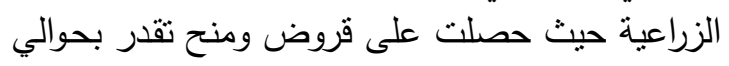

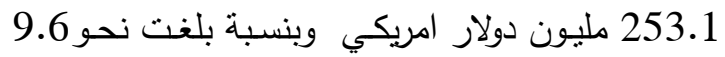

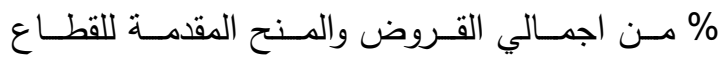

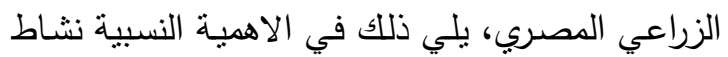

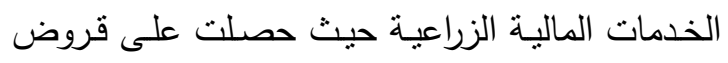

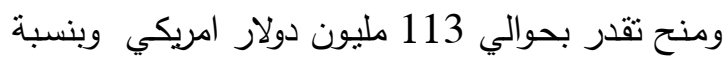

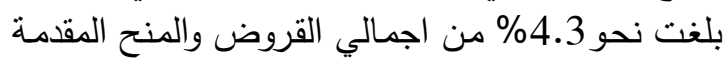
للقطاع الزراعي المصري.

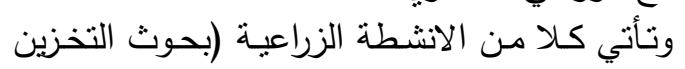

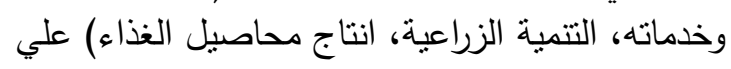

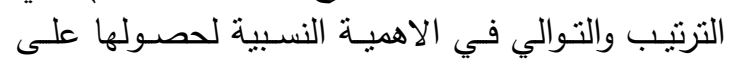

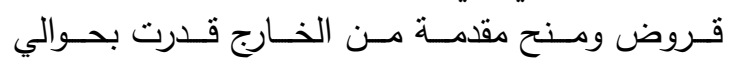

جدول 2. التوزيع القطاعي لقيم القروض و المنح الموزعة علي الانشطة الزراعية المتتوعة خلال الفترة القيمة: ( ب مليون دولار)

(2015-2001)

\begin{tabular}{|c|c|c|}
\hline نسبة النشاط الزراعي\% & القيمة المخصصة & النشاط الزراعي \\
\hline 30.3 & 796.673 & الموارد المائية \\
\hline 20.9 & 549.813 & المدخلات الزراعية \\
\hline 16.9 & 443.902 & الموارد الارضية \\
\hline 9.6 & 253.078 & السياسة الزراعية \\
\hline 4.3 & 113.001 & الخدمات المالية الزراعية \\
\hline 3.7 & 97.755 & بحوث التخزين وخدماته \\
\hline 3.6 & 93.733 & التتمية الزراعية \\
\hline 2.4 & 64.189 & انتاج محاصيل الغذاء \\
\hline 1.8 & 48.193 & الامتداد الزراعي \\
\hline 1.5 & 40.2 & المحاصيل التصنيعية \\
\hline 1.4 & 37.826 & معاملات ما بعد الحصاد ومكافحة الآفات \\
\hline 1.2 & 31.253 & التعاونيات الزراعية \\
\hline 1.2 & 31.235 & التعليم والتدريب الزراعي \\
\hline 1.0 & 27.343 & البحوث الزراعية \\
\hline 100 & 22628. & الاجمالي \\
\hline
\end{tabular}

المصدر: جمعت وحسبت من موقع بيانات البنك الدولي على شبكةالانترنت . 


\section{تقييم إقتصادي لمشروع التنمية الريفية المرحلة الثانية كأحد المشروعات الممولة اجنبيا 2117}

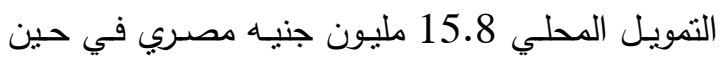
بلغت مساهمة بنك التتمية الافريقي بقرض قالتهن

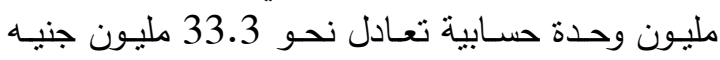

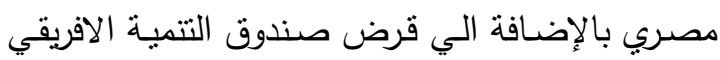
وقيمتهـ 7.4 مليون وحدة حسابية تعـادل نحو 26.4

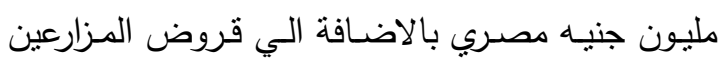

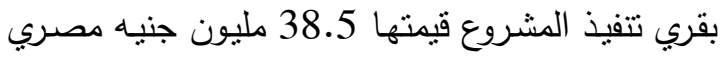

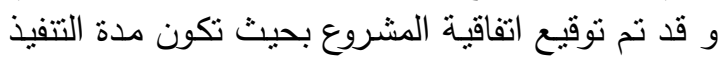

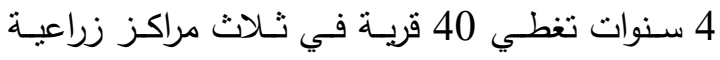

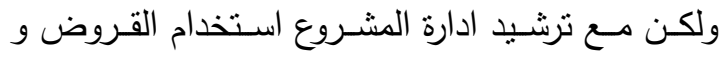

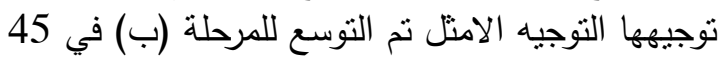

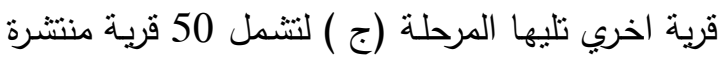

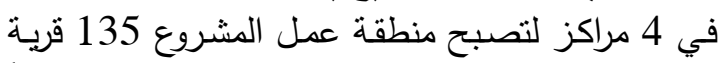
في 10 مراكز زراعية و بذللك فقد حقق المشروع أهدافاً

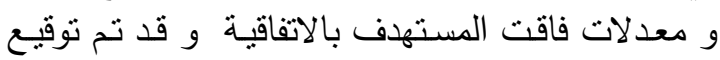

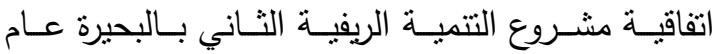

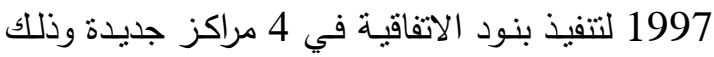

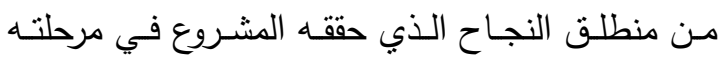

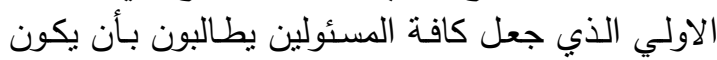

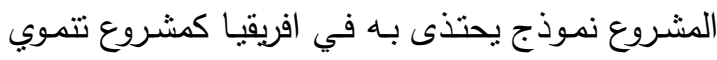

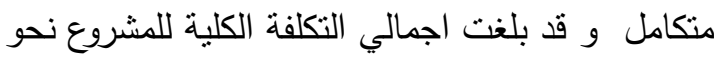

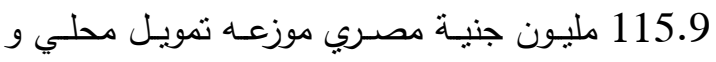

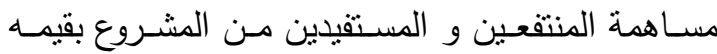
11.8 مليون وحدة حسابية تعادل نحو 55.6 مليون

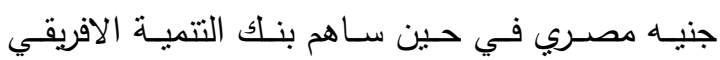
بقرض قيمته 5.34 مليون وحدة حسابية نحو 25.6

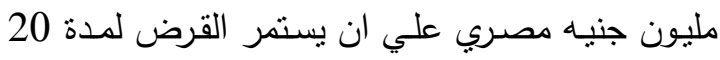

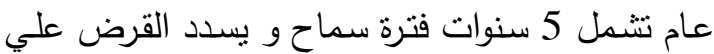

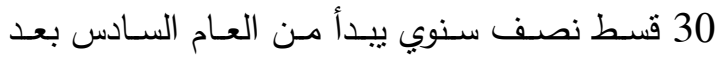

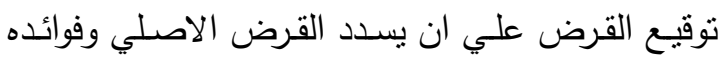

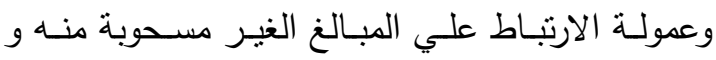

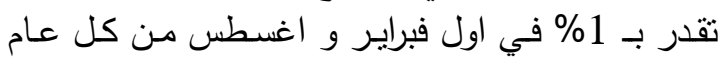

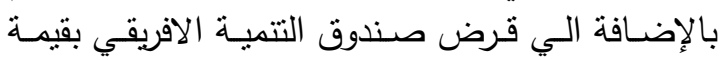

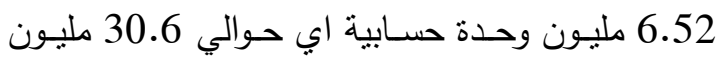

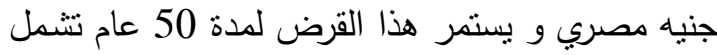

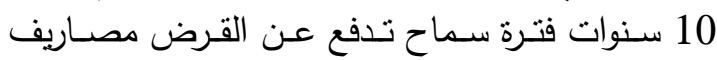
خدمية 0.75\% سنوية عن المبالغ المسحوبة و ون الرصيد

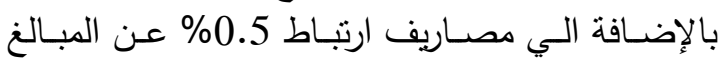

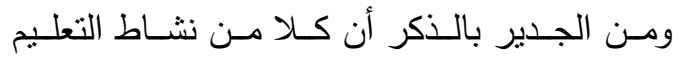

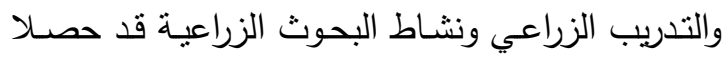

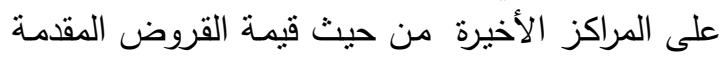

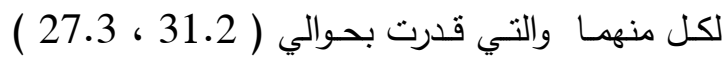
مليون دولار امريكي على نفس الترتيب وبنسبة بلغت

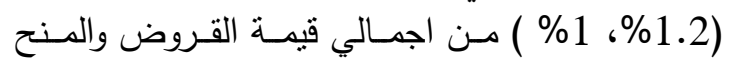

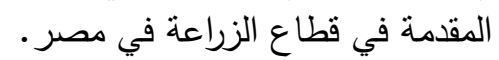
وتري الدراسة ان يجب الزراعة في الدولة تكثيف جهودها

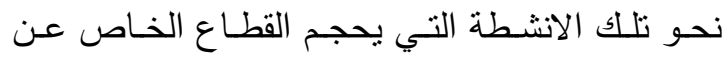

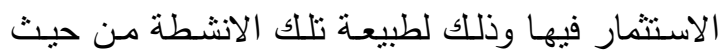

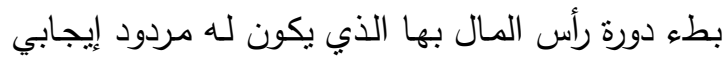
وعائد اقتصادي على كافة الانشطة والدجالات السابقة

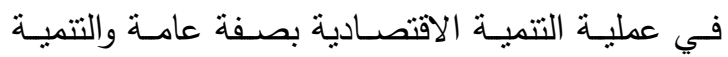

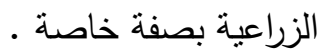

\section{تقييم مشروع التنمية الريفية بالبحيرة}

يعتبـر مشـروع التتميـة الريفيـة بـالبحيرة مـن اوائـل

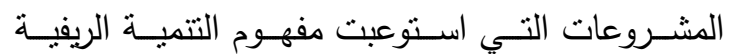

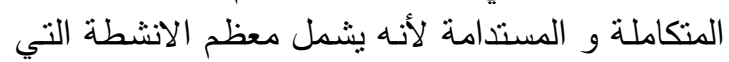

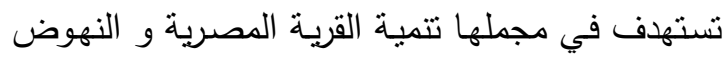

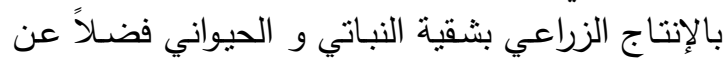

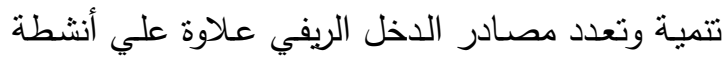

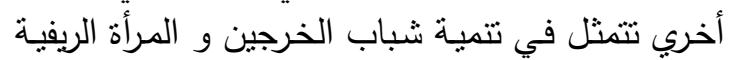

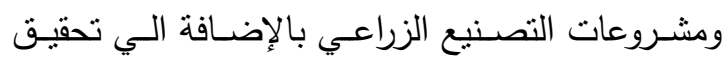

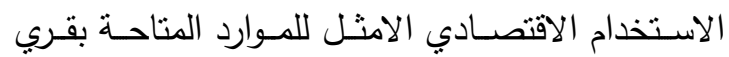
المشروع و تحقيق التكامل بين المزارع و ثرواته النباتية التئية

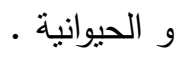

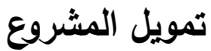

تم توقيع اتفاقية مشروع التتمية الريفية بالبحيرة في

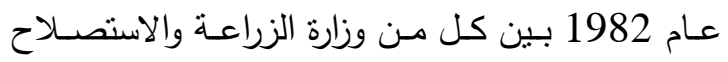

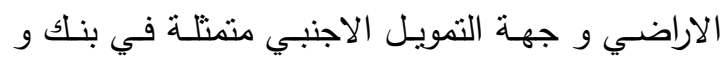

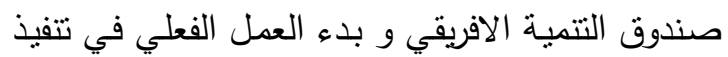

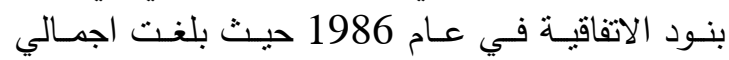

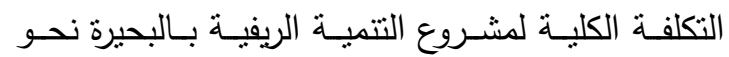

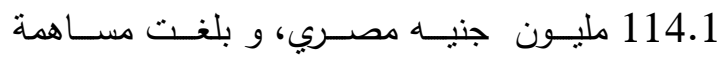


عدة مجـالات منهـا مجـال الخـمات الزراعيـة والبنيـة الاساسية والتوعية البيئية.

اولا: انجـازات مشـروع التنميـة الريفيـة بـالبحيرة فـي

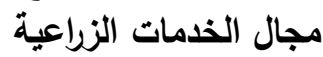

ساهم مشروع التتمية الريفية بالبحيرة من خلال عدة الزية

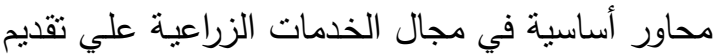
خدمات زراعية بشكل فعال ومؤثر وقد تمثلت انجازات التية

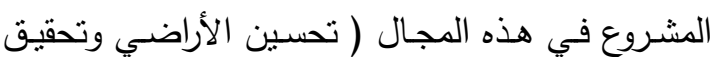

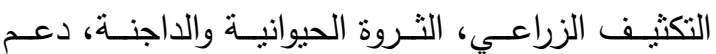
الارشاد الزراعي والنهوض بالإنتاج الزراعي، التدريب، الانشط التكميلية).

المحسور الاول: دعـم الارشــاد الزراعـي والنهــوض

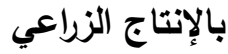

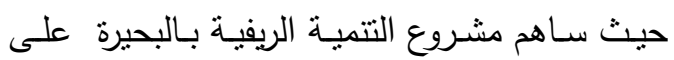
تتفيذ مجموعة من التوصيات والبرامج الارشتادية والفنية التية التي تحقق أهداف خطة عمل المشروع وذلك من خلال

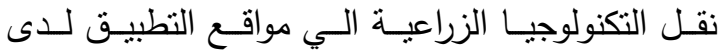

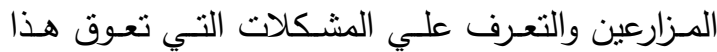

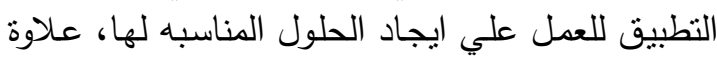
على ذللك تدريب الجهاز الإرشادي وقيادات المزارعين لتتمية قدراتهم في استيعاب وتطبيق التكنولوجيا الزراعية

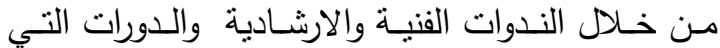

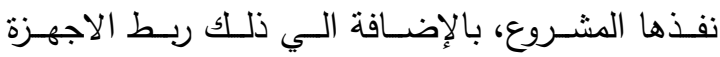
الخدمية المعنية بالمزارعين و الجهاز الارشادي واجهزة

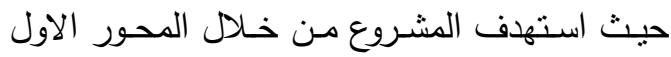
مكون دعم الارشاد الزراعي النهوض بالإنتاجية الفدانية

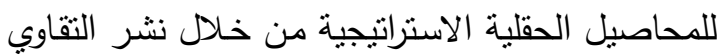

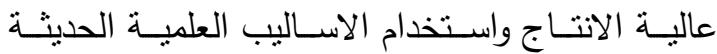

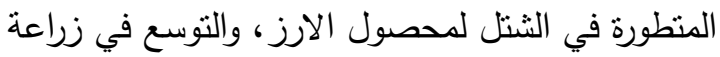
المحاصيل الصيفية الخضراء والتوسع في زراعة الذرة الذرة

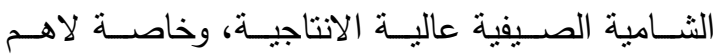

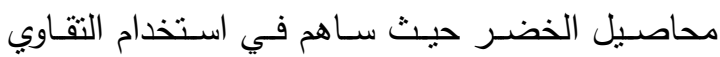
عالية الانتاج علاوة عي ذلك نشر الاصناف الحديثة

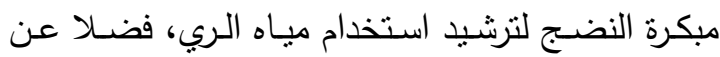
ذللك ادخال المخصبات الحيوية

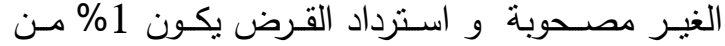

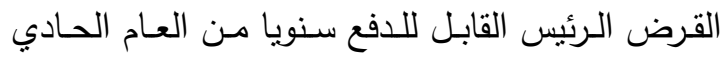

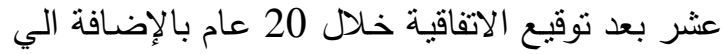

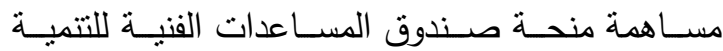
بالمليون وحدة حسابية نعادل 4.7 مليون جنيه مصري.

\section{توصيف مناطق عمل مشروع التنمية الريفية بالبحيرة}

قسمت مناطق عمل المشروع التتمية الريفية بالبحيرة

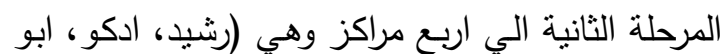

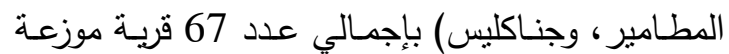

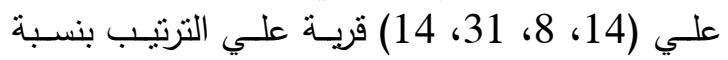
بلغت نحو (20.9\%، 11.9\%، 46.3\%، 20.9\%)

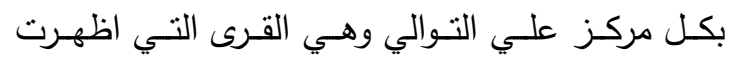

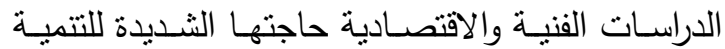

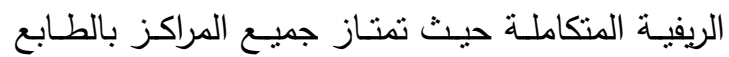

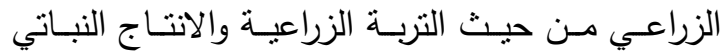

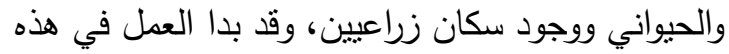
القري منذ عام 2000الي عام 2013.

\section{نتائج الانجازات المحققة من المشروع}

طبقا لما ورد في التقارير الخاصـة بمشروع التتميـة

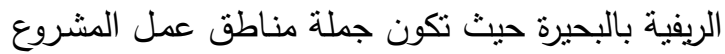

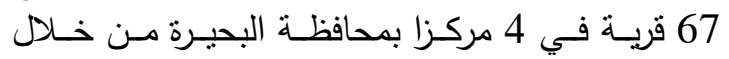
البرامج والاهداف التي سعي لها مشروع التتمية الريفية

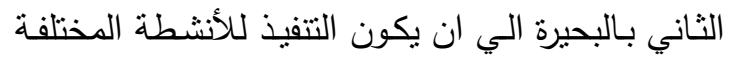

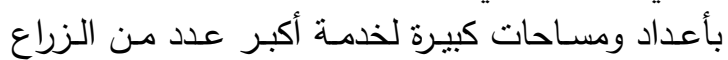

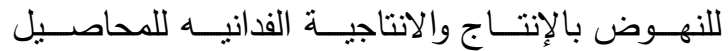

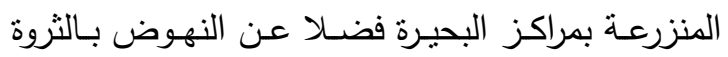

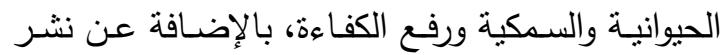

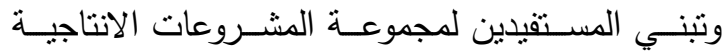

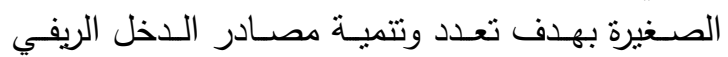
والتوسع في تعميم مشروعات التصنيع الزراعي وتتمية تهية

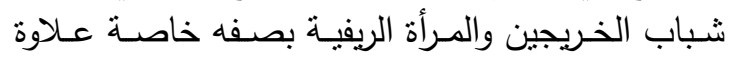

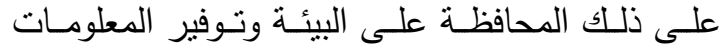
التسويقية التي تساعد المزارعين في تسويق محصولهائه

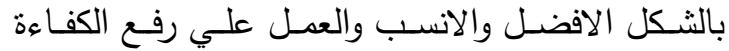
التسويقية، حيث ساهم المشروع بشكل واضح ومؤثر في 


\section{تقييم إقتصادي لمشروع التنمية الريفية المرحلة الثانية كأحد المشروعات الممولة اجنبيا 2119}

(1) نشـاط تربيـة النحل: اهتم المشـروع بهذا النشـاط

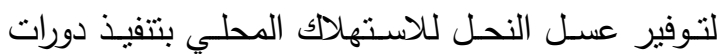

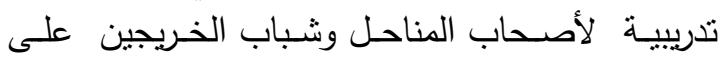

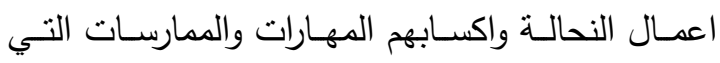

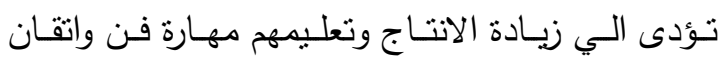

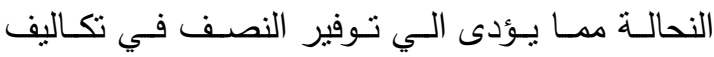

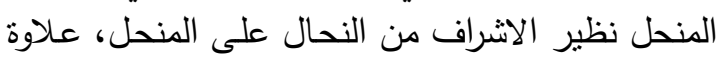

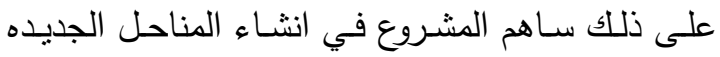

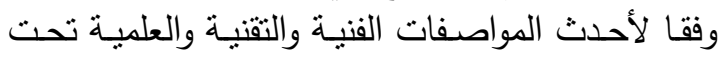

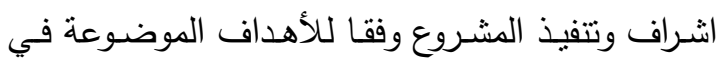

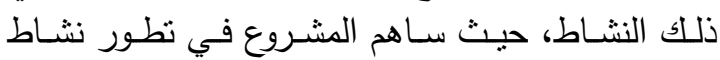

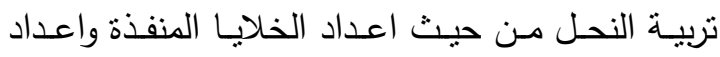

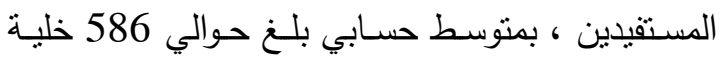

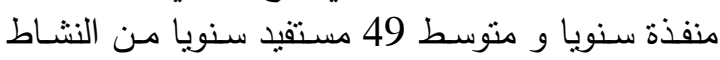
خلال الفترة (2001-2013) بحد اقصي 800 خلئية

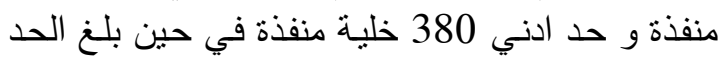
الاقصي لعدد المستفيدين 70 مستقيد و حد ادني 19

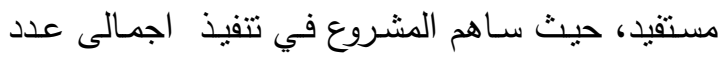

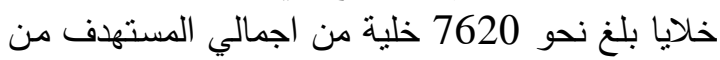

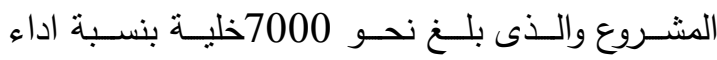
المشروع بلغت نحو 109 \% عن ما هو مستهدف في

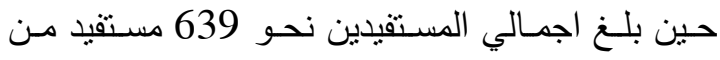

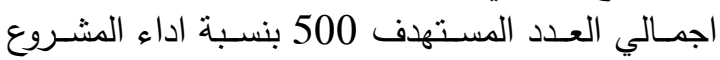

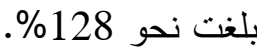

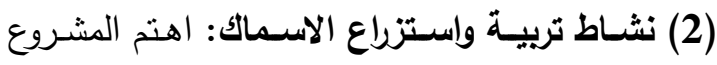

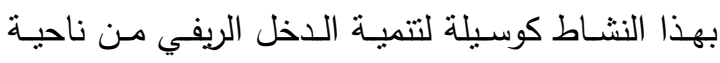

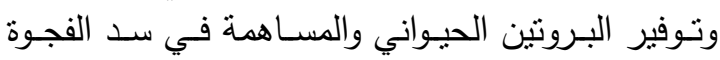

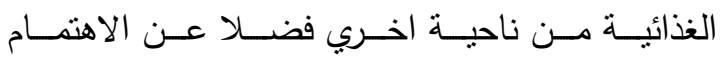

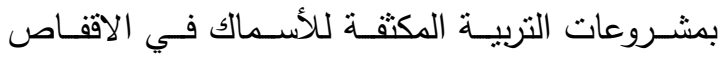

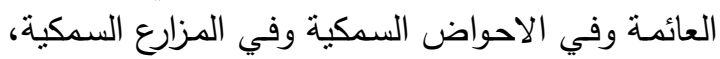

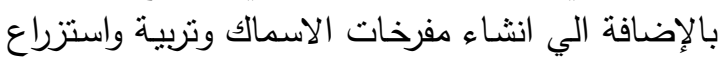

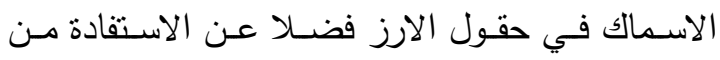

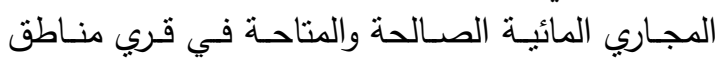

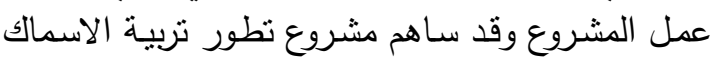

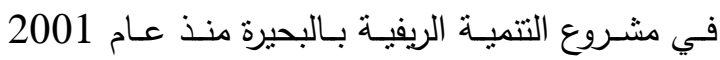

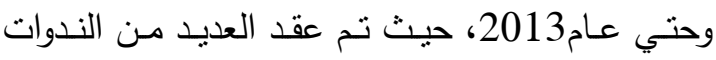
الارشادية في هذا النشاط، كما تم الانتهاء من حن حصاد النداد

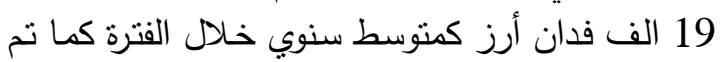
استزراع اسماك المبروك بها بمتوسط بلغ نحو 62 كجم
وســاهم المشـروع فـي مجــال النهـوض بالإنتــاج

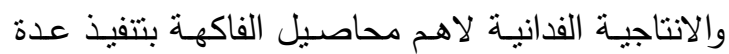
دورات تدريبة للزراع علي أحدث الاستاليب العلمية في الفي

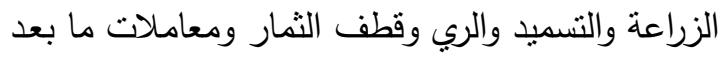

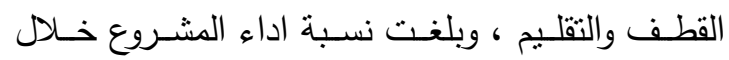

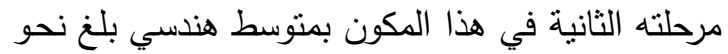

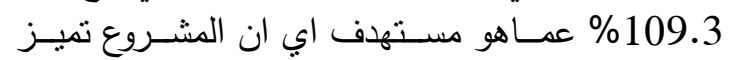

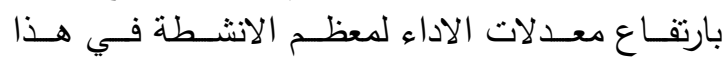

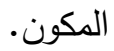

المحسور الثـاني: تحسين الاراضـي وتحقيـق التكثيف الزراعي

سـاهم المشروع في تتفيذ هذا المحور بعدة وسـائل

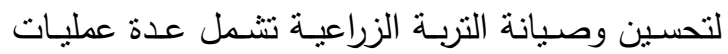
تشمل الحرث العميق واضافة الجبس الزراعي والتسوية

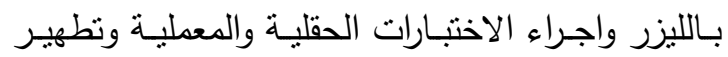

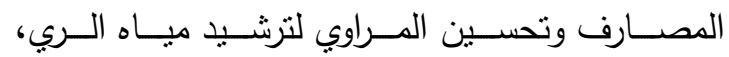

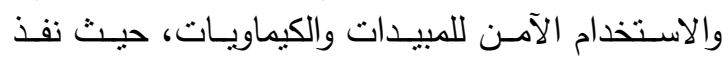

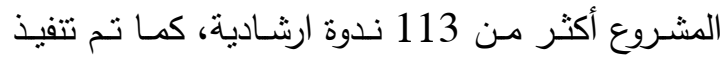

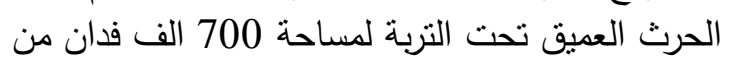

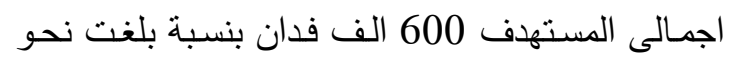

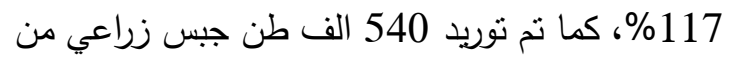

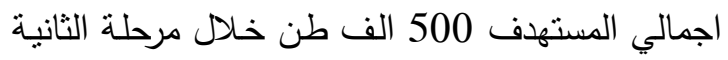
بنسبة بلغت 108\%، علاوة على ذلك تم تتفيذ عمليات نطهير شبكات الري والصرف تخدم مساحة 250 الف فلف تلفي فدان ومتابعة صيانة وتطهير الترع والمصارف العمومية تلانية التي تعترض عمليات تحسين الاراضي.

المحور الثالث: الانشط التكميلية تضمن هذا المحور عدة مكونـات استتهدفت نشـر

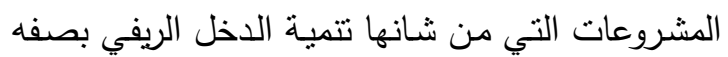

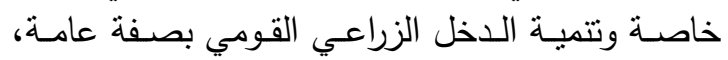
فضـلا على ذلك تحقيق الاكتفاء الذاتي للزراع وأسرهم

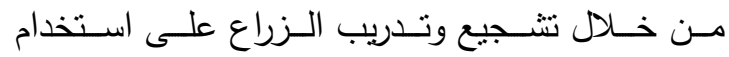
الاساليب العلمية الحديثة المنطورة وتم ذلك من خلاندل تتفيذ عدد من الانشطة على النحو التالي: 


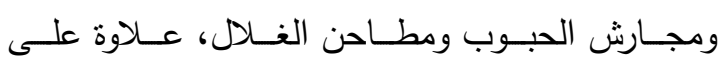

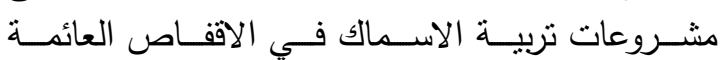
والاحواض السمكية. (6) نشاط تنمية المرأة الريفية: استهدف المشروع رفع الأه المستوي الاجتماعي والاقتصادي والثقافي والصحي تلئي والغذائي ومحو الامية وذلك من خلائل تتفيذ عدة برامج متتوعة للمرأة الريفية، فضلا علي ولية ذلك اكساب المرأة مهارات عملية جديدة في عدة مجالات الخياطة والتريكو والتطريز وشغل الإبرة والكروشيه والصناعات الغذائية والريفية وتصنع منتجات الالبان، ساهم المشروع بتوفير

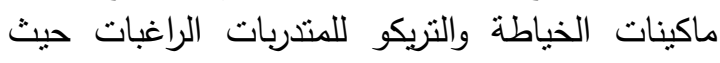
تقوم المتدربة بدفع ربع ثمن الماكينة والباقي علي اقساط شهرية على مدار عام ونصف العام، بالإضافة لفية الي ذلك تقديم حوافز ارشادية للمتدربات تتمثل في مدار وني مجموعة ادوات خياطه وبعض الاقمشة لكل مندربة، فضلا علي مساهمة المشروع بحصص تدربيية للتعليم على ماكينات التريكو وتقديم انوال خثبية صغيرة كتحفيز ارشادي للمتدربات في مجال الكروشيه حيث ساهم المشروع في تتفيذ اجمالى عدد البرامج التدريبية 178 برنامج بمتوسط 14 برنامج سنوي في حين بلغ الغ عدد المتدربات 15020متدربة من اجمالي المستهدف فئ فئن من المشروع والذى بلغ نحو 15000 مندربة بنسبة

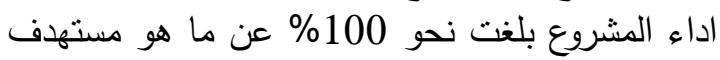
في حين بلغ اجمالي عدد مكينات الخياطة 2750 ماكينة خياطة بمتوسط سنوي بلغ نحو 212 ماكينة سنويا من اجمالي العدد المستهدف 2500 ماكينة خياطة بنسبة اداء المشروع بلغت نحو 110\% .
سمك/ فدان، حيث سـاهم المشـروع في تتفيذ اجمالى مئى

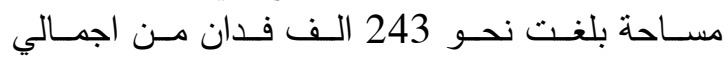

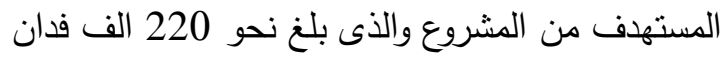
بنسبة اداء المشروع بلغت نحو 110 \% في حين تم تتفيذ عدد 110 مزرعة سمكية بمساحة 530.25 فدان

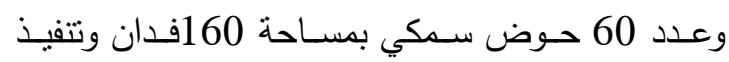
عدد290 بطاريـة باحجـام مختلفـة تعـادل 9320 قفصـا

(3) نشـاط تربيـة دودة الحريـر التوتيـة: كمدخل جديد

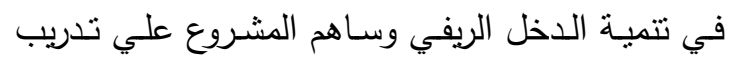

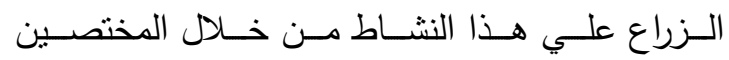
ومساعدتهم علي تسويق انتاجهم من الثرانق.

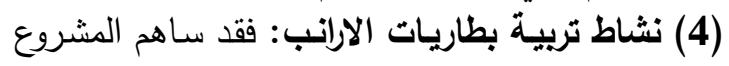
في تطور هذا النشاط في مشروع التتمية الريفية بالبحيرة حيـث بلـنغ متوسـط عـد البطاريـات التي تم تسـكينها

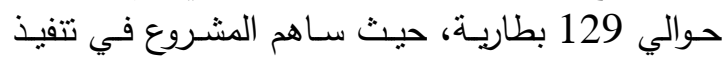
اجمالى عدد بطاريات تم تسكينها بلغت نحو 1675

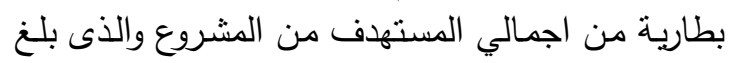

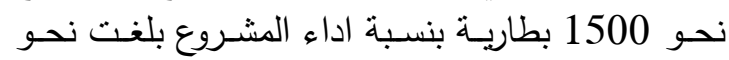
112 \% عن ما هو مستهدف.

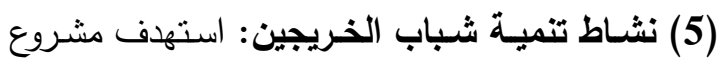

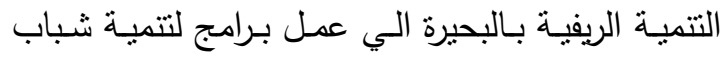
الخريجين بقري عمل المشروع للمساهمة في حل مشكلة

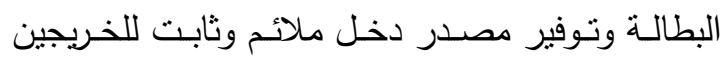
بمختلف تخصصاتهم وتدربيهم على الدخول في العديد من الانثطة أهمها التربية الحديثة للأرانب في بطاريات

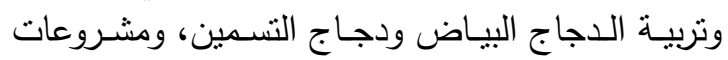

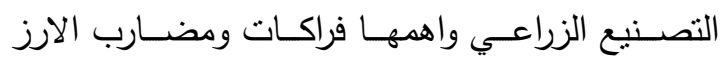


تقييم إقتصادي لمشروع التنمية الريفية المرحلة الثانية كأحد المشروعات الممولة اجنبيا 2121

جدول 3. يوضـح تطور الانشطة المنفذة بمشروع التنميـة الريفية بـالبحيرة المرحلـة الثانيـة خـلال الفترة (2001-

(2013

\begin{tabular}{|c|c|c|c|c|c|c|c|c|}
\hline \multicolumn{2}{|c|}{ تربية الاسماك } & \multicolumn{2}{|c|}{ تربية النحل } & \multicolumn{3}{|c|}{ تنمية المرأه الريفية } & \multirow{2}{*}{ تريبة الارانب } & \multirow{2}{*}{ النشاط } \\
\hline كتوبط الفدان & بـ الالف فـذة فانة & | المستفدين & الخلايا & ماكينة & المتدريات & $\begin{array}{c}\text { البرامج } \\
\text { التدريبية } \\
\end{array}$ & & \\
\hline 58.2 & 12 & 22 & 380 & 211 & 935 & 11 & 106 & 2001 \\
\hline 59.5 & 10 & 53 & 540 & 234 & 931 & 11 & 117 & 2002 \\
\hline 60.3 & 12 & 41 & 410 & 27 & 1136 & 13 & 140 & 2003 \\
\hline 61.3 & 12.5 & 61 & 610 & 302 & 1156 & 14 & 158 & 2004 \\
\hline 63 & 20 & 70 & 700 & 300 & 1373 & 15 & 212 & 2005 \\
\hline 63 & 20 & 60 & 600 & 307 & 1498 & 16 & 191 & 2006 \\
\hline 62 & 15 & 60 & 600 & 243 & 1582 & 17 & 125 & 2007 \\
\hline 62.3 & 24 & 60 & 600 & 171 & 1386 & 16 & 121 & 2008 \\
\hline 62 & 25 & 50 & 800 & 168 & 1037 & 13 & 80 & 2009 \\
\hline 61.5 & 25 & 40 & 400 & 195 & 886 & 11 & 100 & 2010 \\
\hline 61.75 & 22.5 & 51 & 800 & 227 & 990 & 13 & 125 & 2011 \\
\hline 62 & 20 & 52 & 800 & 192 & 1110 & 15 & 125 & 2012 \\
\hline 63 & 25 & 19 & 380 & 173 & 1000 & 13 & 75 & 2013 \\
\hline- & 243 & 639 & 7620 & 2750 & 15020 & 178 & 1675 & منفذ فعلي \\
\hline 62 & 19 & 49 & 586 & 212 & 1155 & 14 & 129 & متوسط \\
\hline - & 220 & 500 & 7000 & 2500 & 15000 & - & 1500 & مستهدف \\
\hline - & $\% 110$ & $\% 128$ & $\% 109$ & $\% 110$ & $\% 100$ & - & $\% 112$ & اداء \\
\hline
\end{tabular}

المصدر: الادارة العامة للمشروع، وحدة الثئون المالية والادارية، قاعدة بيانات المشروع.

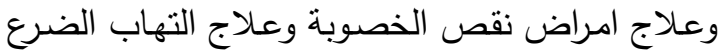

المحور الرابع: الثروة الحيوانية والداجنة

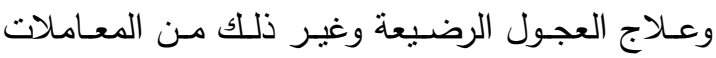

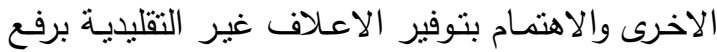

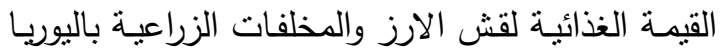

استهدفت خطة عمل المشروع رفع الكفاءة الانتاجية

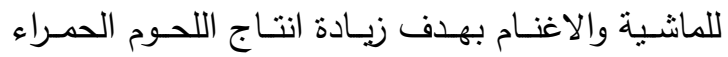

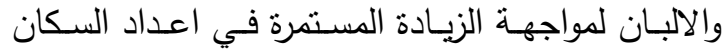

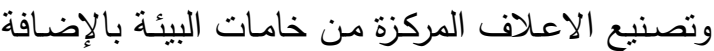

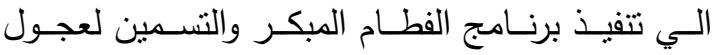

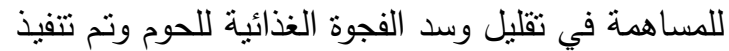

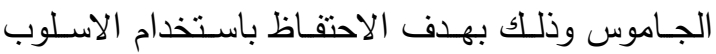

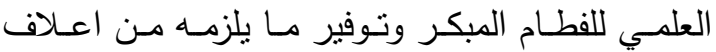

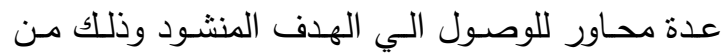

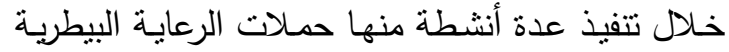

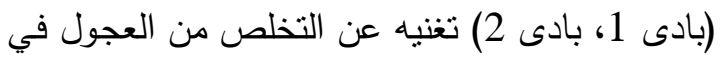
المكثفه والتحصينات للأغنام والماعز والتحصينات منها التهات

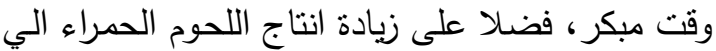

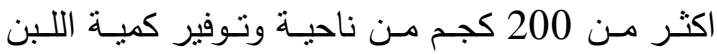

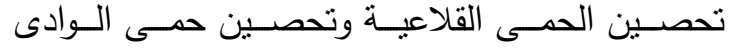

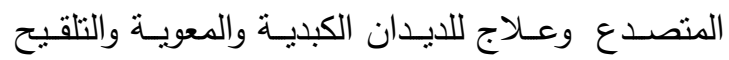
المستخدم في رضـاعة العجل تصل الي 3/2 الكميـة الصـناعي للماثـية والرعايـة البيطريـة واختبـار الحمـل والئل 


\section{ثانيا: انجازات البنية الاساسية}

تتمثنل أهم مـا تم انجـازه وتتفيذه مـن اعمال البنيـة

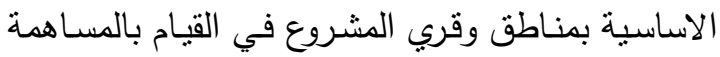

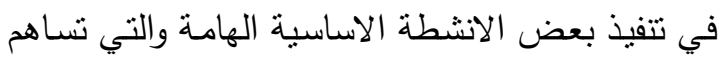
بشكل فعال في تحقيق التتميـة الريفيـة المتكاملـة وذلك الته

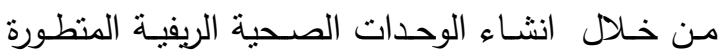

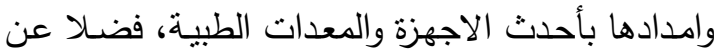
انشاء مراكز طبية متخصصة وتجهيزها والتها وخاصة مراكز لعلاج امراض الكبد والكلى ومتابعة 22 وحدة صحية، وناهة 42 وحدة بيطريـة بالإضـافة الي قيـام المشـروع بتمهيد

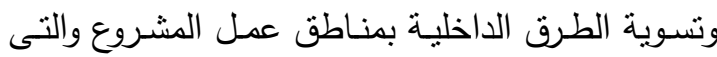

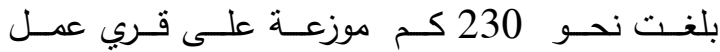

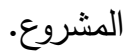

\section{ثُالثا: انجازات التوعية البيئية}

حيث تتاولت خطط وبرامج مشروع التتمية الريفية

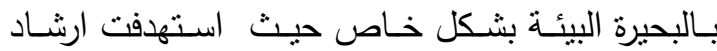
الـزراع الـي الاســاليب المختلفـة للحفـاظ علـى البيئسة

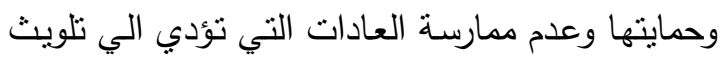

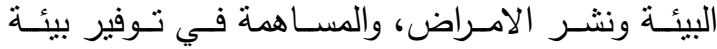

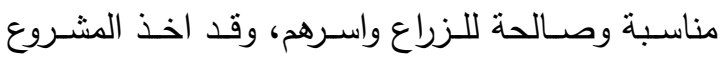

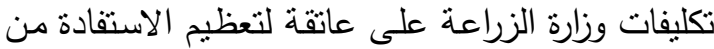
وحدة المساحة الارضية والاستفادة القصوى من الوحدة الناءة

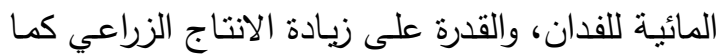

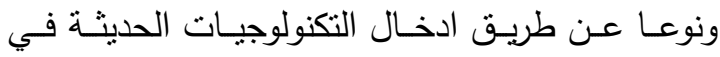

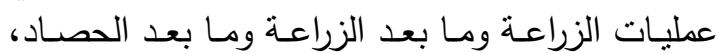
والتركيز على زيادة القدرة التصديرية للمحاصيل غير التراعير

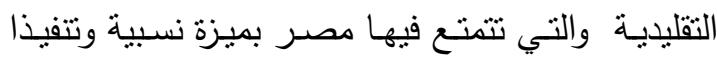

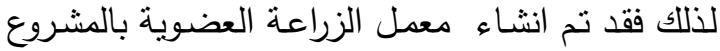

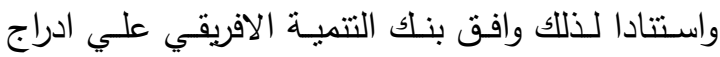

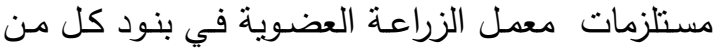

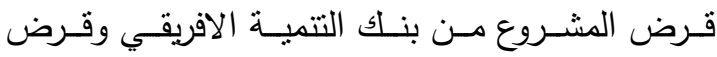

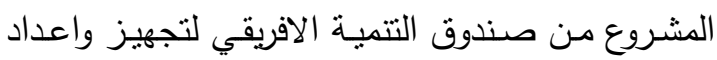
معمل للزراعة النظيفة بمقر المشروع.
المستهكة للعجل في حالة الفطام الطبيعي،علاوة علي

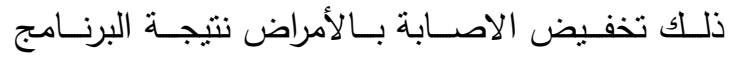

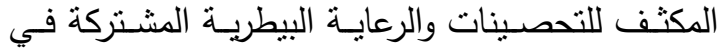

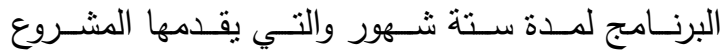
بالمجان، بالإضـافة الي ذلك امداد الزراع المستقيدين

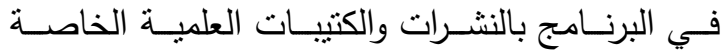

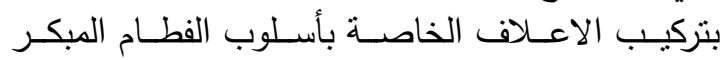

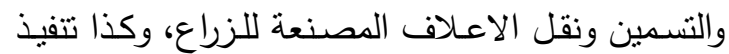

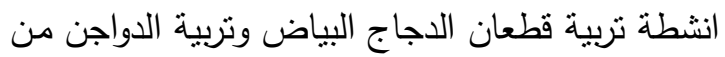

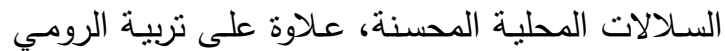
والبط من الاصناف عالية الانتاجية. المحور الخامس : نشاط التدريب

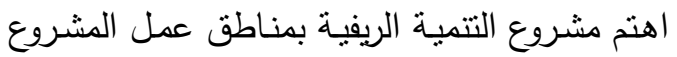

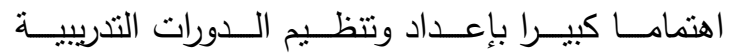

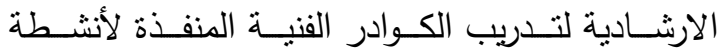

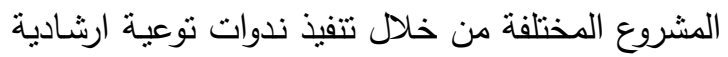

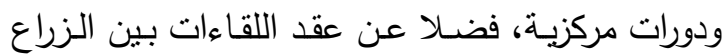

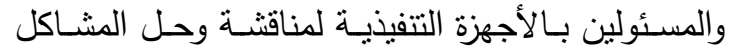

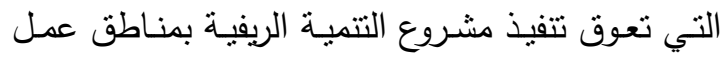

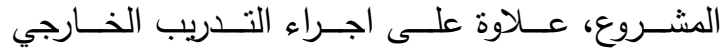

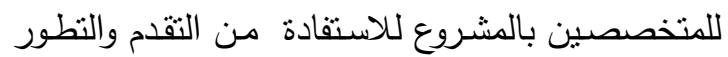

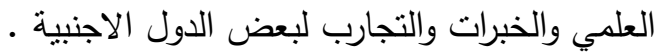
وكما ساهم المشروع في اجراء دورات مكثقة لتوعية

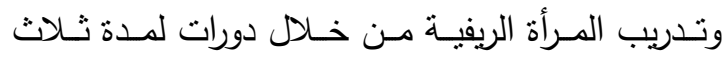
اسابيع في انشطة الحياكة والتطريز والتصنيع الغذائي

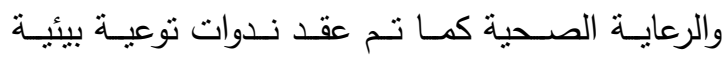
وصحية على شكل سلسلة من الاجتماعات بكل قرية، بالإضـافة الي تتظيم دورات تدريبيـة للأطباء البيطرين

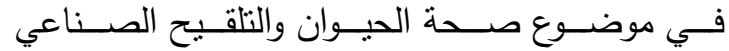
والتحصينات المكثفة، ويضاف الي ذللك تتظيم الدورات لمجموعة المرشدين الزراعيين من المحافظة في العديد المات

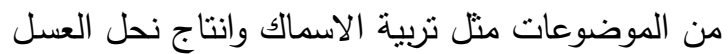
والتوعية البيئية ومكافحة الآفات والامراض. الاضماك 


\section{تقييم إقتصادي لمشروع التنمية الريفية المرحلة الثانية كأحد المشروعات الممولة اجنبيا 2123}

استخدام اسلوب تحليل النفقة / المنفعـة او مـا يسـي بالتحليل الاجتماعي للمنفعة / العائد

التقييم المالي لأنثطة مشروع التنمية الريفية الثاني

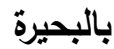

والغرض مـن التقيميم المـالي للمشـروع هـو اختبـار

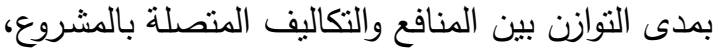

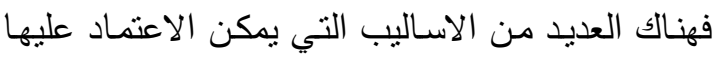

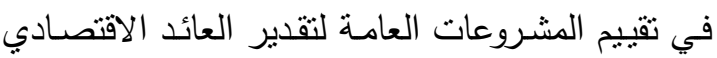

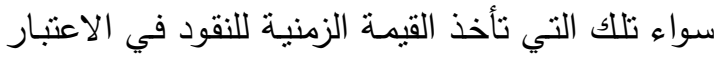
او التي لا تأخذها في الاعنبار .

جدول 4. القيمة الكلية للتكاليف المتغيرة السنوية لمشروع التتمية الريفية بالبحيرة الثاني من 2000 الى الى 2013 بالمليون جنيه التينة بانية

\begin{tabular}{|c|c|}
\hline التكاليف المتغيرة & السنوات \\
\hline 1.631 & 2000 \\
\hline 2.147 & 2001 \\
\hline 2.968 & 2002 \\
\hline 3.631 & 2003 \\
\hline 6.841 & 2004 \\
\hline 8.446 & 2005 \\
\hline 8.731 & 2006 \\
\hline 7.789 & 2007 \\
\hline 6.231 & *2008 \\
\hline 4.111 & 2009 \\
\hline 4.965 & 2010 \\
\hline 4.621 & 2011 \\
\hline 4.666 & 2012 \\
\hline 2.441 & 2013 \\
\hline 69.22 & الإجمالي \\
\hline
\end{tabular}

(*) تم اضافة بند تكاليف تجديد واحلال الاثاث. المصدر: الادارة العامة للمشروع- وحدة الثشئون المالية والادارية بالمشروع الادرة العنارع
التقيـيم المـالي والاقتصـادي لمشـروع التتمبـة الريفيـة بالبحيرة(المرحلة الثانية)

يركز هـا الجزءء مـن التقيبم الاقتصـادي والمـالي

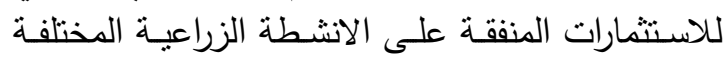

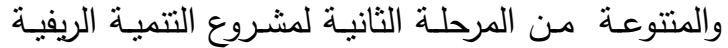

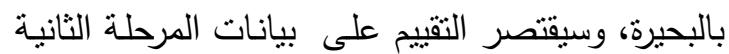

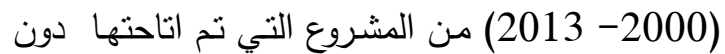

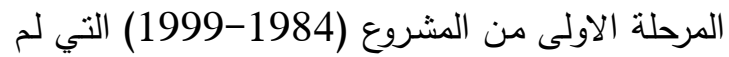

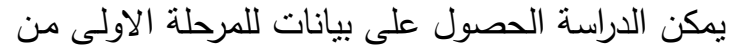

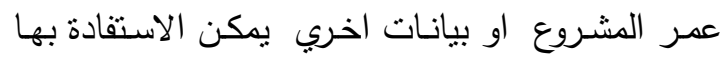

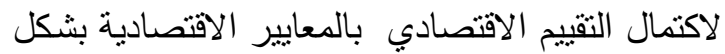
مكتمل، ونتير الدراسة الي ان سعر الخصم خلادل فترة

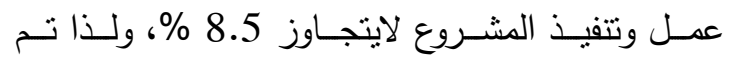
استخدام سعر الخصم عند 10\% علما بان سعر الفائدة على القرض لاتتجاوز الواحد الصحيح ولهذا السبب تم استخدام سعر الخصم عند 10\% فضـلا عن ذلك كون الته

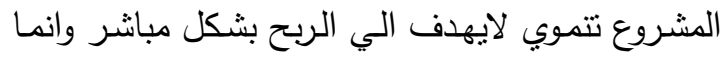

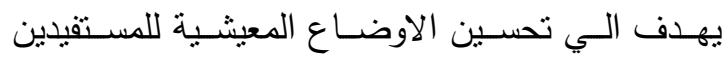
وتقديم ندوات ودورات وانشطه تهدف الى تلميـة البينـة الاساسية للمناطق المستهدفه.

ومسن الملاحظ ان مشـروع التتميـة الريفيـة المرحلـة المئة

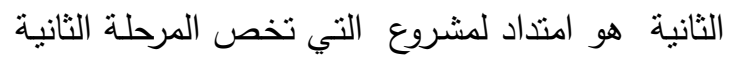

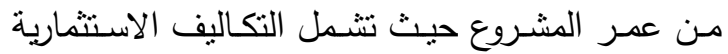

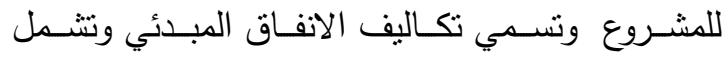

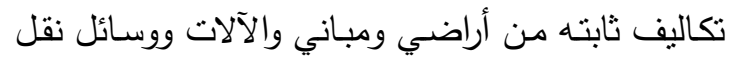
والاتاث والتجهيزات التي انفقها مشـروع التتمية الريفيـة التية

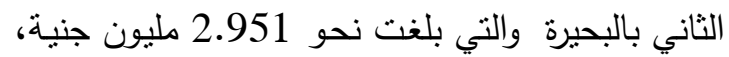
وتتشمل التكاليف المتغيرة وتسمي تكاليف التشغيل من

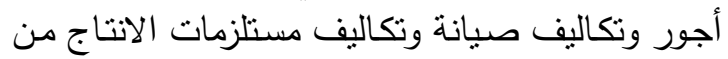

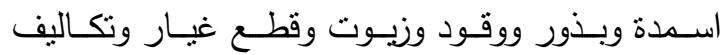

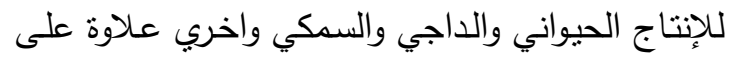

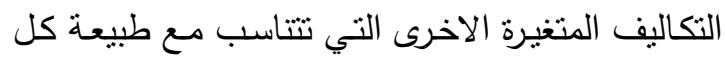

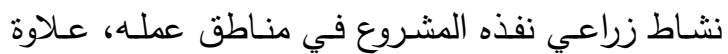

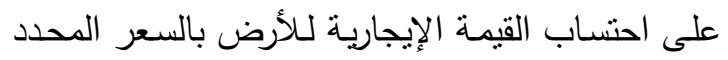
في المنطقة ذاتها اثثاء تتفيذ المشروع •

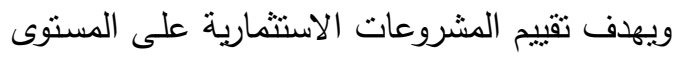

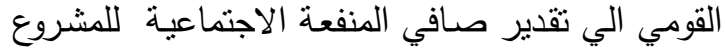

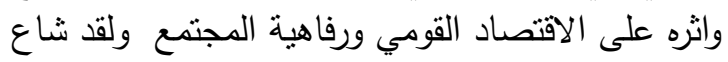


(4) العائد على الجنيه المستثمر

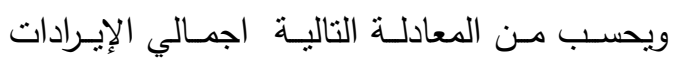
مقسوما على أجمالي المصروفات

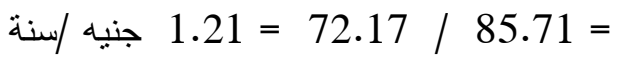
ويتضـح من نتائج المعادلة ان كل جنيه مستثر

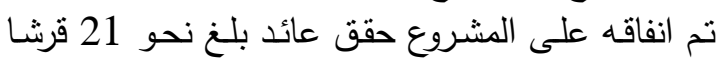

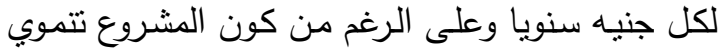

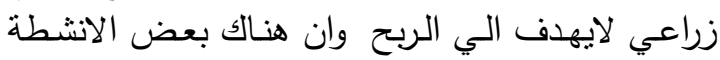

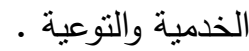

ثانيـا : الاســاليب التــ تأخـــ القيمـة الزمنيـة للنقـود (المعاييز المخصومة: الاسبالي)

(1) نسبة المنافع الحالية الي التكاليف الحالية

وتحسب من المعادلة الأتية اجمالي القيمة الحالية

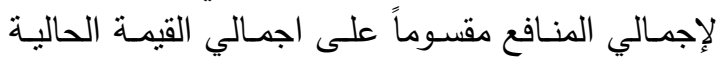
لأجمالي التكاليف الحالية عند سعر خصم $1.13=58.08 / 65.79=$

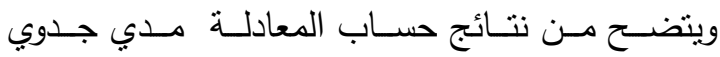
الاستثمارات المنفقة على المشـروع في مرحلته الثنانيـة

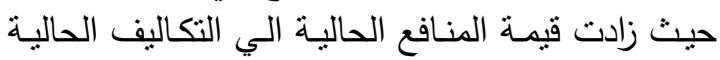
عن الواحد الصحيح.

\section{(2) القيمة الحالية للمنافع الصافية}

وتم التعبيـر عنهـا رياضـيا في الصـورة الرياضـية

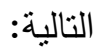
القيمة الحالية الصافية = أجمالي القيم الحالية للمنافع ـ اجمالي القيم الحالية للتكاليف 65.79 - 58.08 = 7.71 مليون جنيه

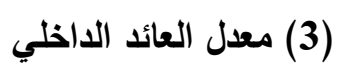

ويعبر معدل العائد الداخلي بشكل ادق عن الكفاية

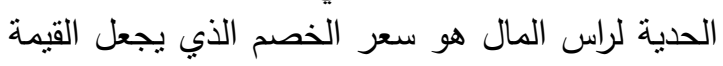

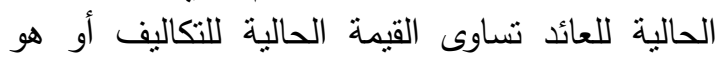
المعدل الذي يجعل القيمة الحالية للتدفقات النقالية للندية النية
اولا: الاسـاليب التـي لا تأخـــ القيمـة الزمنيـة للنقود (المعاييز غير المخصومة الاسيال) (1) نقطة التعادل للمشروع ان تحليـل نقطـة التعـادل مـنهج لتخطيط الربحيـة

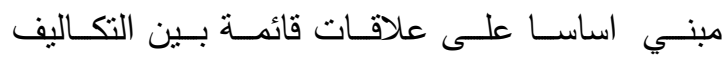

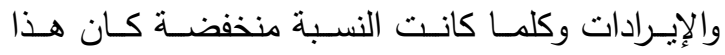

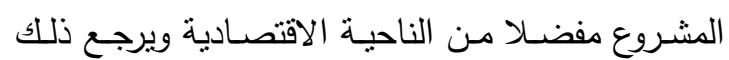

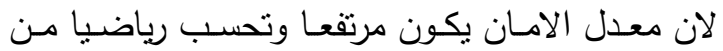

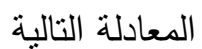

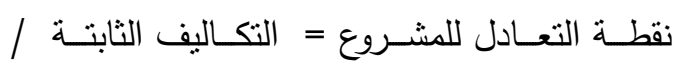
(الإيرادات الكلية ـ التكاليف المتغيرة) $0.16=(69.22-87.51) / 2.95=$ ويتبن من نتائج المعادلة ان هذا المشـروع مـأمن

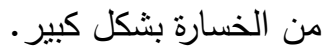

$$
\text { (2) فترة استرداد أموال المشروع }
$$

من المعايير التي تمكن من الحكم علي مدي جدوي

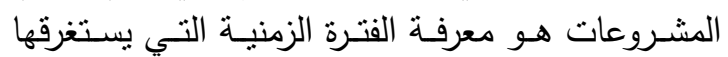

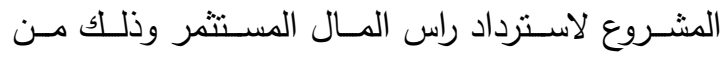

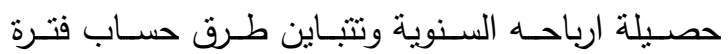

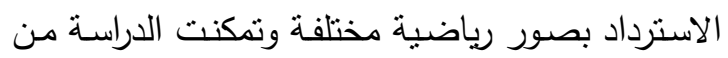

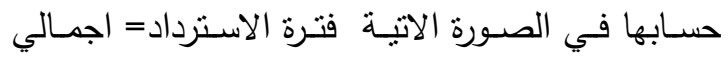
الاستثمارات مقسوما علي متوسط الربح السنوي النقاني $2.7=1.10 / 2.95=$ اي ان المشروع نجح في استرداد التكاليف الثابتـة بعد عامين ونصف تقريبا وهي فترة جيدة جدا بالإنشارة

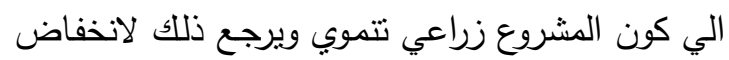

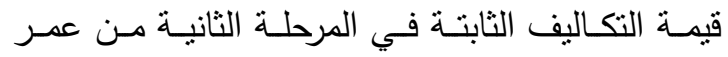

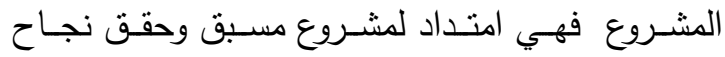
ونتائج ايجابية ملموسة وواضحة في المرحلة الاولي.

$$
\text { (3) معدل الاخل السنوي للمشروع }
$$

ويتم احتساب هذا المؤشر وفقا للمعادلة التالية

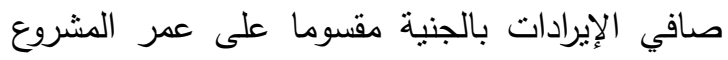
بالسنة 


\section{القيمة المضافة الصافية}

حيث حقق المشروع قيمة مضافة للمستفيدين بلغت نحو 23.62 مليون جنيه في حين حقق قيمة مضافة

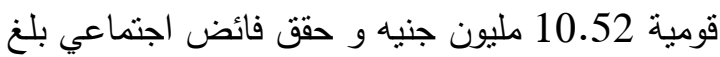

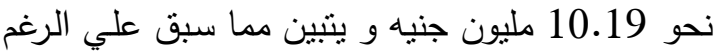

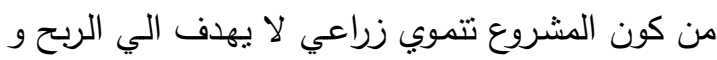

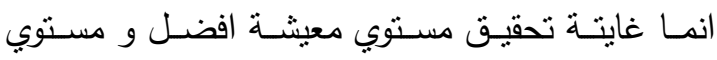

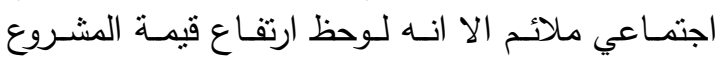

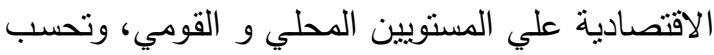

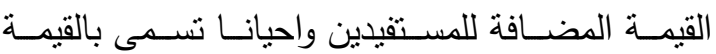
المضافة المحلية من المعادلة التالية :

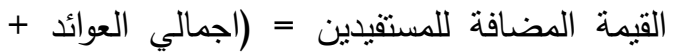

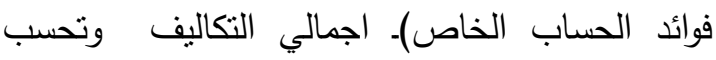
القيمة المضافة القومية من المعادلة التالية:

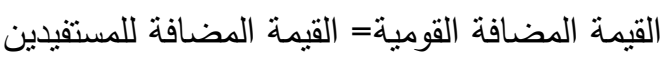
ـ المدفوعات المحولة للخارج

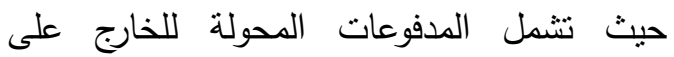

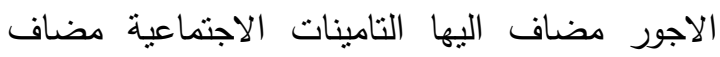
اليها فوائد القرض ويحسب الفائض الاجنماعي من الاعن إئان

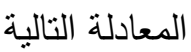
الفائض الاجتماعي= القيمة المضافة القومية ــ الاجور
الخارجة مساوية للصفر ويستخدم هذا المعدل في كل

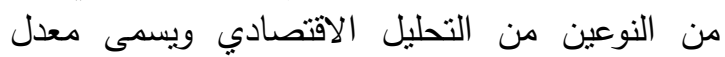
العائد الداخلي الاقتصادي (EIRR) (Economic ) (Internal Rate Of Return المالي يطلق عليه معدل العائد الداخلي المالي Financial Internal Rate of Return ) (FIRR) ) ومن الملاحظات الهامة في هذا المعيار هوان العلاقة

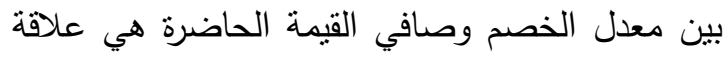

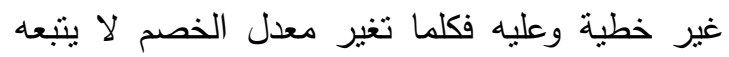

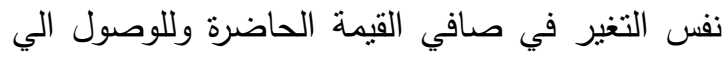
معدل اكثر دقة يضل استخدام فارق بسيط بين سعري الخصم لا يتعد 2\% دولة ويحسب من المعادلة التالية

$$
\frac{V N P_{1}\left(P_{2}-P_{1}\right)}{V N P_{1}+V N P_{2}}+P_{1}=I R R
$$

حيث: IRR = معدل العائد الداخلي سعر الخصم الاصغر سعر الخصم الاكبر الاصنر القيمة الحالية لصافي التدفقات النقدية عند

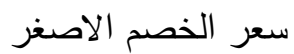

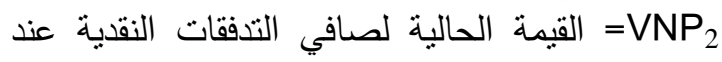
سعر الخصم الاكبر.

$$
\% 12.33=\frac{4.17(10-5)}{4.17+(-1.33)}+5=I R R
$$


جدول 4. إجمالي النكاليف و الايرادات لمشروع التتمية الريفية بالبحيرة المرحلة الثانية عند سعري خصم 5\%، بالئ 10\% بالمليون جنيه

\begin{tabular}{|c|c|c|c|c|c|c|c|}
\hline لصني التدفة الحالية & $10 \%$ & لصنيمة الحالية & $5 \%$ & التدفقات & الايردات & التكاليف & السنوات \\
\hline-3.76 & 0.909 & -3.94 & 0.952 & -4.14 & 0.44 & 4.58 & 1 \\
\hline-1.21 & 0.826 & -1.32 & 0.907 & -1.46 & 0.69 & 2.15 & 2 \\
\hline-1.63 & 0.751 & -1.87 & 0.864 & -2.17 & 0.80 & 2.97 & 3 \\
\hline-0.84 & 0.683 & -1.01 & 0.823 & -1.23 & 2.40 & 3.63 & 4 \\
\hline-1.87 & 0.621 & -2.36 & 0.784 & -3.01 & 3.84 & 6.84 & 5 \\
\hline-1.89 & 0.564 & -2.49 & 0.746 & -3.34 & 5.10 & 8.45 & 6 \\
\hline-1.47 & 0.513 & -2.04 & 0.711 & -2.86 & 5.87 & 8.73 & 7 \\
\hline-0.18 & 0.467 & -0.26 & 0.677 & -0.38 & 7.41 & 7.79 & 8 \\
\hline 1.93 & 0.424 & 2.93 & 0.645 & 4.55 & 10.78 & 6.23 & $9^{*}$ \\
\hline 2.04 & 0.386 & 3.24 & 0.614 & 5.28 & 9.39 & 4.11 & $10 * *$ \\
\hline 2.41 & 0.350 & 4.03 & 0.585 & 6.88 & 11.85 & 4.97 & $11 * *$ \\
\hline 2.37 & 0.319 & 4.14 & 0.557 & 7.43 & 12.05 & 4.62 & 12 \\
\hline 2.03 & 0.290 & 3.71 & 0.530 & 7.01 & 11.67 & 4.67 & 13 \\
\hline 0.73 & 0.263 & 1.40 & 0.505 & 2.78 & 5.22 & 2.44 & 14 \\
\hline-1.33 & & 4.17 & & 15.34 & 87.51 & 72.17 & المجموع \\
\hline
\end{tabular}

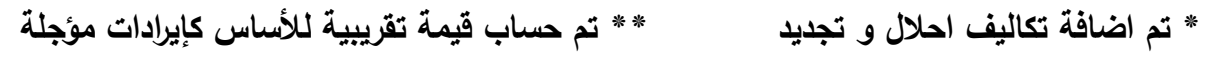

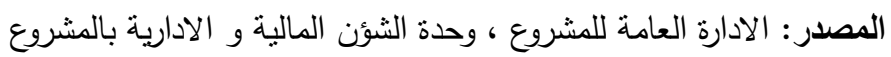




\section{تقييم إقتصادي لمشروع التنمية الريفية المرحلة الثانية كأحد المشروعات الممولة اجنبيا 2127}

جلول 5. القيمة المضافة المحلية و القومية و الفائض الاجتماعي لمشروع التتمية الريفية بالبحيرة المرحلة الثانية خلال الفترة (2000-2013) بالمليون جنيه

\begin{tabular}{|c|c|c|c|c|c|c|c|c|c|c|c|}
\hline \multirow[b]{2}{*}{ الاجتماعي } & \multirow[b]{2}{*}{ القافة القومية } & \multicolumn{4}{|c|}{ المدفوعات المحولة للخارج } & \multirow[b]{2}{*}{ للمستفيدين } & \multirow{2}{*}{ |التكاليف } & \multicolumn{3}{|c|}{ المخرجات } & \multirow[b]{2}{*}{$\frac{\overline{3}}{9}$} \\
\hline & & اجمالي | & القرض & اجتماعية & "جور & & & | الاجمالي & لخاص الحساب & العائد & \\
\hline-3.72 & 4.37 & 0.68 & 0.01 & 0.02 & 0.65 & -3.69 & 4.58 & 0.89 & 0.45 & 0.44 & 1 \\
\hline-0.94 & 1.63 & 0.75 & 0.02 & 0.04 & 0.69 & -0.88 & 2.15 & 1.26 & 0.58 & 0.69 & 2 \\
\hline-2.18 & 3.27 & 1.67 & 0.25 & 0.33 & 1.09 & -1.60 & 2.97 & 1.37 & 0.57 & 0.80 & 3 \\
\hline-1.67 & 2.83 & 2.35 & 0.75 & 0.44 & 1.16 & -0.48 & 3.63 & 3.15 & 0.75 & 2.40 & 4 \\
\hline-3.52 & 5.59 & 3.31 & 0.75 & 0.49 & 2.07 & -2.28 & 6.84 & 4.56 & 0.72 & 3.84 & 5 \\
\hline-4.29 & 6.47 & 3.73 & 0.75 & 0.80 & 2.18 & -2.74 & 8.45 & 5.70 & 0.60 & 5.10 & 6 \\
\hline-3.43 & 5.22 & 3.29 & 0.75 & 075 & 170 & -1.93 & 873 & 6.80 & 0.93 & 5.87 & 7 \\
\hline-1.26 & 3.35 & 3.75 & 0.75 & 0.91 & 2.09 & 0.40 & 7.79 & 8.19 & 0.79 & 7.41 & 8 \\
\hline 3.81 & -1.62 & 3.64 & 0.75 & 0 & 2.1 & 5.26 & 6 & 11.50 & 0.72 & 10.78 & 9 \\
\hline 4.88 & -2.87 & 3.07 & 0.75 & 0.31 & 2.01 & 5.94 & 4.11 & 10.05 & 0.66 & 9.39 & 10 \\
\hline 6.61 & -5.50 & 1.91 & 0.50 & 0.30 & 1.11 & 7.41 & 4.97 & 12.38 & 0.53 & 11.85 & 11 \\
\hline 7.11 & -6.01 & 1.84 & 0.09 & 0.65 & 1.10 & 7.85 & 4.62 & 12.47 & 0.42 & 12.05 & 12 \\
\hline 6.40 & -5.09 & 2.25 & 0.05 & 0.89 & 1.31 & 7.34 & 4.67 & 12.00 & 0.33 & 11.67 & 13 \\
\hline 2.40 & -1.13 & 1.90 & 0.00 & 0.63 & 1.27 & 3.03 & 2.44 & 5.47 & 0.25 & 5.22 & 14 \\
\hline 10.19 & 10.52 & 34.14 & 6.17 & 7.26 & 20.71 & 23.62 & 72.17 & 95.79 & 8.28 & 87.51 & مج \\
\hline
\end{tabular}

"من واقع البيانات الخاصة بسجلات وتقاريرالمشروع.

المصدر: جمعت و حسبت بواسطة الباحث من جدول (5).

3- ضرورة نوافر البيانات و المعلومات الخاصة بمثل

التوصيات

هذه المشروعات الممولة اجنبياً حتي يتسنى التئي للقائمين علي التقيبم بشكل واضح ودقيق. 1 - صباغة استراتيجية واضحة المعالم حول اولويات

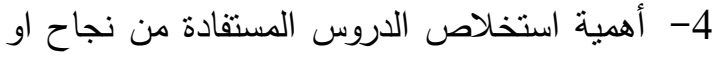

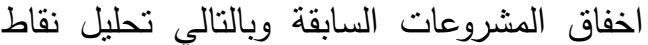
الضعف لتجنبها ونقاط القوة للعمل علي استمرارها وزيادة كفائتها في المشروعات المسنقبلية الممانله. توجيه القروض والمنح الاجنبية الميسرة الي الي الئية

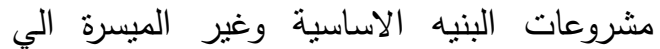
المشروعات الانتاجية. المشروع واشراكهم في الاشراف علي تتفيذ 5- ضرورة تكرار منل هذه المشروعات في مناطق تتمية ريفية زراعية اخري لرفع مستوي المعيشة الشروع كحافز تشجيعي لهم.

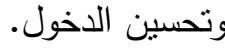




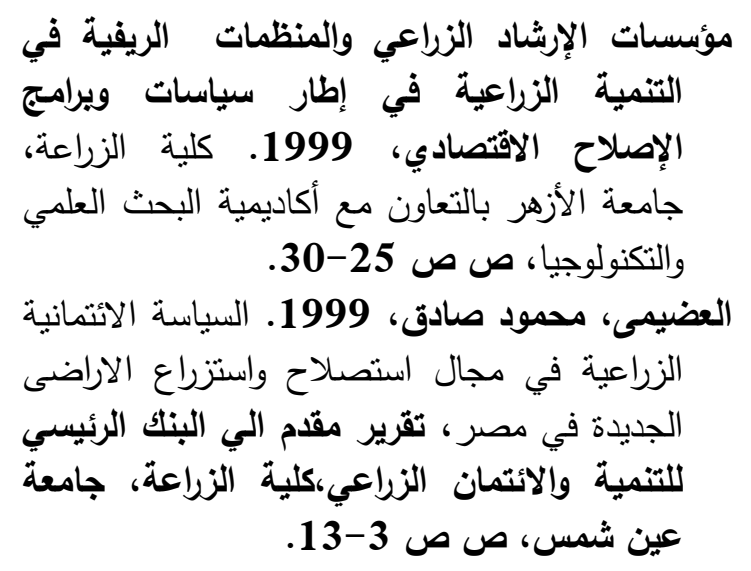

ثانياً: المراجع باللغة الاجنبية

Jody Z.K. 2002. Ray C. Rist Ten Steps to a results- based monitoring and evaluation system. The World Bank, Egypt, 14 p.

Gettinger, J.P. 1998, Economic Analysis of Agricultural Projects, IBRD, Washington, USA, pp. 4-24.
6- يجب قيام الدولة والهيئات المسئولة و الاجهزة

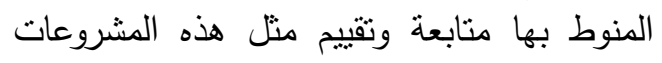

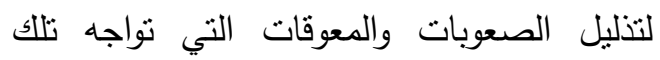

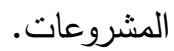
7- نري الدراسة أنه يجب علي الدولة تكثيف جهودها نحو تللك الانشطة التي يحجم القطاع الخاص عن النه

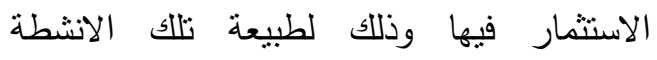
وخاصة (نشاط التعليم والتدريب الزراعي ونشاط

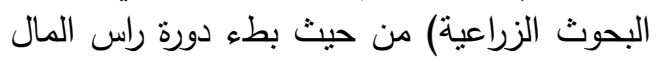

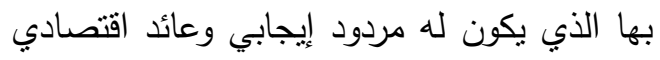

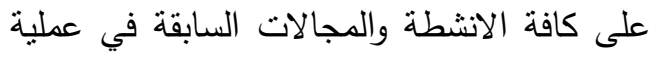
التتمية الاقتصادية بصفة عافة الافة والتجات والتمية الزراعية فية بصفة خاصة.

$$
\text { المراجـع }
$$

اولا: المراجع باللغة العربية

التقارير السنوية والنصف سنوية لمشروع التتمية

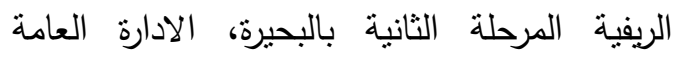

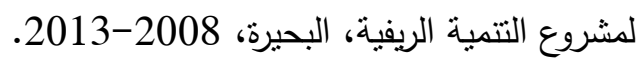
نصار، سعد زكي، 1995. التقييم المالي والاقتصادي، لإني

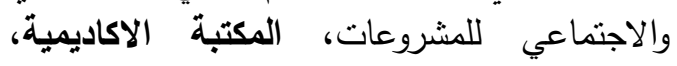
القاهرة، مصر، ص ص ص 5 5-35. 


\title{
ECONOMIC ASSESSMENT OF THE RURAL DEVELOPMENT PROJECT PHASE AS ONE OF THE FOREIGN FUNDED PROJECTS
}

\author{
Ahmed ${ }^{*}$ A.A.A., Mugahid W.A. and Abdel Maqsoud A.M.
}

Agric. Economics Dept., Fac. of Agric., Ain Shams Univ., P.O. Box 68, Hadayek Shobra 11241, Cairo, Egypt

*Corresponding author: Drahmedamir1982@yahoo.com

Received 12 June, $2018 \quad$ Accepted 15 July, 2018

\section{ABSTRACT}

This research was generally aimed at conducting an economic study to evaluate the Beheira Governorate Rural Development Project Phase II, because of the availability of data necessary to carry out the ordinary economic and financial assessment, As one of the leading rural development projects in Egypt financed by of the Bank and the African Development Fund, where research has been aimed at studying the vulnerabilities to avoid them in the future, and strengths to sustain and develop it and increase its efficiency, and this can only be achieved through a systematic scientific assessment of the project.

It was one of the most important findings of the research that the project was characterized by rates of performance exceeding the target of the project in most of its activities. In addition to the feasibility of the project from the point of view of the financial and economic assessment, Despite the fact that the project is an agricultural development and most of its activities are not for profit, Despite the fact that the project is an agricultural development and most of its activities are not for profit, it achieved an internal rate of return of about $12.3 \%$ and achieved a positive net present value of about 7.7 million pounds, and The project has succeeded in recovering its capital in about two and a half years. The project has added value to beneficiaries of about 23.6 million pounds while achieving a national added value of about 10.5 million pounds and the social surplus rate is about 10.2 million pounds, However, it is noted that the project spent a lot of money in the training activity, due to the limited education and lack of expertise among the beneficiaries and the lack of skilled labor, which led the project to pump a large part of the project funding for training activities.

Keywords: Rural development, Economic evaluation, Value added, Income rate, Social surplus.

$$
\text { تحكيم: 1.د أحمد محمد أحمد } 1.1 \text { أداء النوبى أحمد سلامه }
$$


